\title{
Fine tuning neuronal targeting of nanoparticles by adjusting the ligand grafting density and combining PEG spacers of different length
}

Carla Pereira Gomes a,b,c, Victoria Leiro a,b, Cátia Daniela Ferreira Lopes a,b,d, Ana Patrícia Spencer a,b, Ana Paula Pêgo a,b,c,e,*

\author{
a INEB - Instituto de Engenharia Biomédica, Universidade do Porto, Portugal \\ ${ }^{b}$ i3S - Instituto de Investigação e Inovação em Saúde, Universidade do Porto, R. Alfredo Allen 208, 4200- \\ 135 Porto, Portugal \\ ' Faculdade de Engenharia da Universidade do Porto, R. Dr. Roberto Frias, 4200-465 Porto, Portugal \\ ${ }^{d}$ Faculdade de Medicina da Universidade do Porto, Alameda Prof. Hernâni Monteiro, 4200-319 Porto, \\ Portugal \\ e ICBAS - Instituto de Ciências Biomédicas Abel Salazar, Universidade do Porto, Rua de Jorge Viterbo \\ Ferreira 228, 4050-313 Porto, Portugal \\ * Corresponding author at: INEB/i3S, R. Alfredo Allen 208, 4200-135 Porto, Portugal. \\ E-mail address: apego@ineb.up.pt (A.P.Pêgo).
}

Originally published in Acta Biomater. 2018 Sep 15;78:247-259. doi: 10.1016/j.actbio.2018.08.005.

\begin{abstract}
Poly(ethylene glycol) (PEG) has been extensively used to coat the surface of nanocarriers to improve their physicochemical properties and allow the grafting of targeting moieties. Still, to date there is no common agreement on the ideal PEG coverage-density or length to be used for optimum vector performance. In this study, we aimed to investigate the impact of both PEG density and length on the vectoring capacity of neuron-targeted gene-carrying trimethyl chitosan nanoparticles. The nontoxic fragment from the tetanus toxin (HC) was coupled to a $5 \mathrm{kDa}$ heterobifunctional PEG (HC$P E G 5 k$ ) reactive for the thiol groups inserted into the polymer backbone and grafted at different densities onto the nanoparticles. Internalization and transfection studies on neuronal versus nonneuronal cell lines allowed to determine the PEG density of 2 mol\% of PEG chains per mol of primary amine groups as the one with superior biological performance. To enhance $\mathrm{HC}$ exposure and maximize cell-nanoparticle specific interaction, NPs containing different ratios of HC-PEG5k and $2 \mathrm{kDa}$ methoxy-PEG at the same grafting density were produced. By intercalating HC-PEG5k with methoxy-PEG2k we attained the best performance in terms of internalization (higher payload delivery into cells) and transfection efficiency, using twice lower amount of HC. This outcome highlights the need for fine-tuning of PEG-modified nanoparticles towards the achievement of optimal targeting.
\end{abstract}




\section{Statement of Significance}

The amount and exposure of targeting moieties at a nanoparticle surface are critical parameters regarding the targeting potential of nanosized delivery vectors. However, to date, few studies have considered fundamental aspects impacting the ligand-receptor pair interaction, such as the effect of spacer chain length, flexibility or conformation. By optimizing the PEG spacer density and chain length grafted into nanoparticles, we were able to establish the formulation that maximizes cellnanoparticle specific interaction and has superior biological performance. Our work shows that the precise adjustment of the PEG coverage-density presents a significant impact on the selectivity and bioactivity of the developed formulation, emphasizing the need for the fine-tuning of PEG-modified nanoparticles for the successful development of the next-generation nanomedicines.

Keywords: Nanoparticle surface modification/functionalization; PEGylation; Targeted nanoparticles; Spacer length; Cellular uptake

\section{INTRODUCTION}

The primary goal of nanomedicine is to improve clinical outcomes [1]. Towards this end, one of the major challenges in the field is the ability to develop formulations with high efficacy and selectivity towards a desired target. The possibility of engineering nanoparticles (NPs) with appropriate surface chemistries allows for the partitioning of the therapeutic molecules towards the diseased tissues, increasing the payload delivery in the desired areas of action and limiting unwanted side effects [1], [2], [3].

In recent years, we have witnessed the development of an enormous array of systems designed to fulfill these demands. Among all nanocarriers, polymer-based NPs offer significant advantages over other platforms for targeted delivery of drugs, proteins or nucleic acids. Polymeric materials have emerged as a major class of controlled release systems due to their unique physicochemical properties that can be readily manipulated [4]. As a result of this versatility, polymer-based NPs can be formulated to deliver a high range of biomolecules, to allow grafting of different types of ligands into their matrices as well as to be biodegradable. This allows for the tailoring of NPs to achieve active targeting properties that will render them adaptable to multiple clinical settings, with improved efficacy and safety [1], [5].

To promote active targeting, researchers have been using different molecules that possess high affinity towards a unique molecular signature to direct the binding of NPs to receptors differentially expressed on (diseased) tissues or cells, such as antibodies, protein and protein fragments, small molecules, peptides or aptamers [3], [6]. One of the most popular strategy for NP surface grafting of targeting moieties has been through the use of poly(ethylene glycol) (PEG) as a spacer [7]. The addition of this hydrophilic polymer serves different purposes. Other than serving as an intermediate linker/spacer to connect the desired targeting moieties onto NPs, PEG is expected to render these with "stealth" properties, decreasing biofouling by plasma proteins and non-specific immune clearance, and to contribute to the exposure of the targeting moieties at their surface. However, the use of a too dense PEG layer will hinder NP cellular uptake and endosomal escape [8]. This 
phenomenon is recognized as the "PEG dilemma" [9], and consists in achieving the right balance of PEGylation in order to effectively avoid undesired interactions with extracellular components, without compromising cellular uptake by the desired cell population [8], [10].

Our team has been working on the development of a suitable NP to vectorize therapeutic genes to peripheral neurons in a targeted fashion, after a peripheral and minimally invasive administration. For this, we have chosen trimethyl chitosan (TMC) as starting material due to its suitable properties for non-viral gene delivery, namely its biocompatibility and low toxicity, easiness of chemical modification, plasmid DNA (pDNA) condensation efficiency and good solubility at physiological conditions [11], [12]. So far, the obtained results are very promising, as we were able to design a NP with improved stability and adequate degradation kinetics at physiological conditions [12] that is able to specifically interact with neurons [13] and upon internalization suffer retrograde transport [14]. Moreover, in an in vivo setup these NPs were able to accelerate the recovery of a crushed nerve by preventing nerve degeneration and enhancing nerve regeneration in a specific fashion [15]. Hereupon, we went further in optimizing the targeting ligand exposure at the NP surface, as this is a feature of paramount importance to promote maximum cell interaction and NP biological performance.

To date, few studies have considered in conjugation fundamental aspects for targeted NP design such as the effect of the PEG chain length, flexibility and conformation on ligand-receptor interactions. Both the targeting ligand density and PEG conformation at the NP surface - brush or mushroom-like - should be tightly balanced to achieve NP maximum cell interaction and internalization [10], [16]. In fact, the PEGylation of NPs with identical single chains could hinder the ligand free motion, particularly at high PEG densities, resulting in a reduced accessibility of the ligands towards their cellular receptors [17].

Based on the above, the main goal of the present study was first to determine the optimal ligand grafting density and exposure at the surface of polymeric biodegradable NPs, in order to achieve optimal vectoring capacity towards neuron-like cells. For this, we compared in a systematic manner the physicochemical properties and the internalization and transfection efficiency of TMC NPs grafted with the non-toxic and neurotropic C-terminal fragment of the tetanus toxin heavy chain $(\mathrm{HC})$ through the covalent attachment of a $5 \mathrm{kDa}$ PEG spacer (PEG5k) at different densities. After establishing the optimal grafting density, we further investigated the effect of the PEG chain organization on the ligand exposure at the neuron-targeted NPs surface by testing mixed ratios of a HC-tethered PEG (HC-PEG $5 \mathrm{k}$ ) and a shorter methoxy-terminated PEG chain of $2 \mathrm{kDa}$ (MeO-PEG2k). To determine the best NP formulation in terms of cell-specific interaction, we took advantage of imaging flow cytometry, an advanced bioimaging technique with powerful statistical power [12] that allowed us to evaluate the impact of the fine-tuning functionalization of the developed NPs on their internalization and pDNA delivery in different cell lines.

With this work, we show the importance of determining the right PEGylation grafting density and targeting moiety exposure as key parameters for the development of effective targeting non-viral nanocarriers.

\section{Materials and methods}

\subsection{Trimethyl chitosan purification and characterization}


Trimethyl chitosan (TMC) derived from ultra-pure chitosan produced from Agaricus bisporus mushrooms, was provided by Kytozyme (lot VIHAo013-157, Belgium). Prior to use, the polymer was purified by filtration and dialysis and characterized as previously described [12]. The molecular weight was determined by gel permeation chromatography (GPC) to be $43.3 \pm 5.0 \mathrm{~kg} \cdot \mathrm{mol}-1$. Acetylation and quaternization degrees were calculated by $1 \mathrm{H}$-Nuclear Magnetic Resonance (NMR) spectroscopy and found to be $15.7 \pm 0.9 \%$ and $30.1 \pm 4.6 \%$, respectively. Endotoxin levels of the purified polymer extracts were assessed using the Limulus Amebocyte Lysate Assay (OCL-1000, Cambrex Bio Science, USA), following the manufacturer instructions and were found to be $<0.1$ EU.ml-1, respecting the US Department of Health and Human Services guidelines for implantable devices [18].

\subsection{Synthesis of thiolated trimethyl chitosan (TMCSH)}

Partially thiolated TMC (TMCSH) was prepared by reaction between the primary amino groups of purified polymer and 2-iminothiolane, as previously described (Scheme 1a) [14]. Briefly, TMC was dissolved in HEPES buffer ( $20 \mathrm{mM}, \mathrm{pH}$ 7.4) at $5 \mathrm{mg} \cdot \mathrm{ml}-1$. Then, 2-iminothiolane. $\mathrm{HCl}$ (Sigma-Aldrich, USA) was added in order to attain a theoretical modification of $10 \%$ of the polymer primary amines and the $\mathrm{pH}$ of the resulting solution adjusted to 8 with $\mathrm{NaOH}$. The reaction mixture was saturated with argon and magnetically stirred at room temperature (RT) for $6 \mathrm{~h}$. The resulting solution was dialyzed for 3 days against $5 \mathrm{mM} \mathrm{HCl}$ at $4{ }^{\circ} \mathrm{C}$. Thereafter, the dialyzed solution was frozen at $-80^{\circ} \mathrm{C}$ and lyophilized for 3 days, yielding the TMCSH as a white powder, which was stored at $-20^{\circ} \mathrm{C}$ until further use.

\subsection{Determination of polymer thiol content}

The amount of reduced/free thiol groups grafted to the TMC was determined spectrophotometrically using the Ellman's reagent (5,5-dithio-bis-(2-nitrobenzoic acid), DTNB; Sigma-Aldrich, USA) as previously described [14], [19]. An amount of $155.3 \pm 10.1 \mu \mathrm{mol} . \mathrm{g}-1$, corresponding to $4.8 \pm 0.3 \%$ functionalization of TMC primary amines with 4 -mercaptobutan-1-iminium (holding the thiol groups), was achieved.

\subsection{Plasmid DNA}

The pDNA used encoded for the enhanced green fluorescent protein (eGFP) and luciferase (pCMVeGFPLuc, 6.7 kb, Invitrogen, USA) genes. Plasmid was produced in a $\mathrm{DH}_{5} \alpha$ competent E. coli strain transformed with the respective plasmid under the cytomegalovirus (CMV) promoter. Subsequently, pDNA purification was performed using an EndoFree Plasmid Giga Kit following the manufacturer instructions (Qiagen, Germany). Plasmid concentration and purity were assessed by ultraviolet spectroscopy (Nanodrop 1000, Thermo Scientific, USA). Only plasmid solutions with an absorbance ratio $(260 / 280 \mathrm{~nm})$ comprised between 1.8 and 2.0 were used.

\subsection{HC production, purification and modification}

The HC fragment was produced recombinantly using the BL21 E. coli strain as previously described by Sinha et al. [20]. The plasmid encoding for the HC fragment, together with a coding sequence for 
six histidines in the N-terminal, was a kind offer from Prof. Neil Fairweather (King's College, UK). The purified $\mathrm{HC}$ fragment was covalently linked to a $5 \mathrm{kDa}$ heterobifunctional PEG spacer bearing a $\mathrm{N}$ hydroxysuccinimide (NHS) ester and a maleimide (MAL) end groups (JenKem Technology, USA), as described elsewhere [15], [19]. Briefly, amine groups from HC fragment reacted with the succinimidyl ester group (NHS) through stable amide bonds (Scheme 1 b). To assess the PEGylation degree of HC, firstly the modified protein was purified using a $50 \mathrm{kDa}$ centrifugal filter unit (EDM Millipore, USA) to ensure the removal of free PEG from solution. Subsequently, the amount of reactive MAL groups from the PEG spacer linked to the HC protein was determined using a modified Ellman's assay [19], [21], and found to be $1.9 \pm 0.4 \mathrm{~mol} P E G / \mathrm{mol} \mathrm{HC}$. Hereafter, the HC functionalized with PEG-MAL will be designated as $\mathrm{HC}-\mathrm{PEG} 5 \mathrm{k}$.

\subsection{Nanoparticle preparation}

\subsubsection{Nanoparticle core}

Polymer-pDNA nanocomplexes were prepared by mixing, while vortexing, equal volumes of pDNA (1 mg.ml-1) and TMCSH (2.5 mg.ml-1) solutions (both in $20 \mathrm{mM} \mathrm{HEPES} \mathrm{buffered} \mathrm{saline} \mathrm{(HBS)} \mathrm{with}$ $5 \%(\mathrm{w} / \mathrm{v})$ glucose solution, $\mathrm{pH}$ 7.4). TMCSH NPs core were let to stabilize for $15 \mathrm{~min}$ at RT before further functionalization. Nanocomplexes with different molar ratios of quaternized amine groups $(N)$ to moles of DNA phosphate groups $(P)-N / P$ ratio - were prepared.

\subsubsection{Nanoparticle functionalization}

After NP core preparation and stabilization, NPs were either functionalized to produce non-targeted NPs (nT NPs) by grafting a 5 kDa methoxy-PEG-MAL (MeO-PEG $5 \mathrm{k}$, Sigma-Aldrich, USA), or to generate neuron-targeted NPs (Tg NPs), by grafting HC-PEG5k (HC-PEG5k-MAL) into the NPs (Scheme 1C).

For the ligand density optimization, thiol-functionalized NPs (suspended in $20 \mathrm{mM} \mathrm{HBS}$ with $5 \%(\mathrm{w} / \mathrm{v}$ ) glucose) were functionalized with PEG-MAL, by a thiol-ene Michael-type addition reaction, in 1, 2 or $4 \mathrm{~mol} \%$ of the TMC primary amino groups (MeO-PEG5k or HC-PEG5k). For the ligand exposure optimization, mixtures of HC-PEG5k-MAL and a 2 kDa MeO-PEG-MAL (MeO-PEG2k, JenKem Technology, USA) were used at 1:1, 2:1 and 1:2 molar proportion (HC-PEG5k:MeO-PEG2k). After addition of any of the ligands (PEGs and HC-PEG) mentioned above, the NPs were left at $37^{\circ} \mathrm{C}$ and 800 rpm overnight (Thermomixer ${ }^{\circledR}$, Eppendorf ${ }^{\circledR}$, Germany), before further use.

The efficiency of HC-PEG $5 k$ and MeO-PEG $2 k$ binding to the NPs was assessed by means of size exclusion chromatography (SEC) in an AKTA Purifier 10 system (GE Healthcare Bio-Sciences AB, Sweden). Due to issues related to the detection limit of the applied UV detector of the SEC system, the NPs used to carry out these coupling efficiency experiments were prepared at N/P 8 by complexing $48 \mu \mathrm{g}$ of pDNA in the case of Tg NPs, and $384 \mu \mathrm{g}$ of pDNA for Tg NPs with hetero PEG brushes. After the functionalization, the unreacted free PEGs (HC-PEG5k and MeO-PEG $2 \mathrm{k}$ ) were separated from NPs by centrifugation (2200 rpm for $45 \mathrm{~min}$ ) using a $100 \mathrm{kDa}$ cut-off filter (Vivaspin ${ }^{\circledR}$ 20, Sartorius, Germany), and washed twice with $20 \mathrm{mM} \mathrm{HBS}$ with $5 \%(\mathrm{w} / \mathrm{v})$ glucose solution $\mathrm{pH} 7.4$ (2 times the initial volume of the NPs). The eluted solutions/supernatants were collected and analyzed by SEC on a SuperoseTM 12 column (10/300 GL) (Amersham Biosciences Corporation, Sweden) using $20 \mathrm{mM} \mathrm{HBS}$ buffer with $150 \mathrm{mM} \mathrm{NaCl}, \mathrm{pH} 7.4$, as eluent at a flow rate of $0.5 \mathrm{ml}$.min-1. Aliquots of

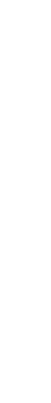


$50 \mu \mathrm{l}$ were injected and the eluent fractions monitored by UV detection at $280 \mathrm{~nm}$ and $225 \mathrm{~nm}$. The total amount of $\mathrm{HC}-\mathrm{PEG} 5 \mathrm{k}$ and $\mathrm{MeO}-\mathrm{PEG}_{2} \mathrm{k}$ in the supernatants were quantified from the integration of their corresponding peaks on the SEC chromatograms (see Supplementary Fig. S1).

\subsection{Determination of nanoparticles hydrodynamic size and zeta potential}

Complexes were prepared as described above. Eight $\mu \mathrm{g}$ of pDNA was used for each formulation. The zeta potential and size of the complexes were assessed using a Zetasizer Nano Zs (Malvern, UK) following the manufacturer's instructions. The Smoluchowski model was applied for zeta potential determination and cumulant analysis was used for mean particle size determination. All measurements were performed in triplicate, at $25^{\circ} \mathrm{C}$.

\subsection{Plasmid DNA condensation efficiency and polyplexes stability in physiological conditions}

Plasmid DNA condensation efficiency was assessed through the SYBR ${ }^{\circledR}$ Gold (Life Technologies, Thermo Fisher Scientific, USA) exclusion assay, as previously described [12]. This assay enables the measurement of free pDNA, due to $\mathrm{SYBR}^{\circledR}$ Gold binding to free nucleic acids (not complexed into NPs). Both binary and ternary complexes were prepared and further diluted in the respective preparation buffer to assess the ability to complex nucleic acids. Furthermore, polyplexes stability under physiological conditions was evaluated. For this purpose, $20 \mu \mathrm{l}$ of complexes prepared with a pDNA concentration of $25 \mathrm{ng} . \mu \mathrm{l}-1$ (in a final volume of $100 \mu \mathrm{l}$ ) were incubated with $178 \mu \mathrm{l}$ Dulbecco's Modified Eagle Medium (DMEM) medium with Glutamax, supplemented with $10 \%(\mathrm{w} / \mathrm{v})$ fetal bovine serum (FBS) (heat inactivated at $57^{\circ} \mathrm{C}$ for $30 \mathrm{~min}$ ) and $1 \%$ Pen/Strep (10,000 U.ml-1 penicillin and $10,000 \mu \mathrm{g} \cdot \mathrm{ml}-1$ streptomycin) (all supplied by $\mathrm{Gibco}^{\circledR}$, Thermo Fisher Scientific, USA), in a blackwalled 96-well plate (Greiner Bio-One, Austria). Then, $2 \mu$ l of a 10-fold diluted (Tris-acetate-EDTA TAE Buffer) SYBR ${ }^{\circledR}$ Gold solution was added to each well to reach a final volume of $200 \mu \mathrm{l}$. After $10 \mathrm{~min}$ incubation with continuous plate mixing, fluorescence was measured ( $\lambda$ exc $=485 \mathrm{~nm}$, $\lambda e m=540 \mathrm{~nm}$, Synergy Mx Microplate Reader (BioTek, USA)). Results are expressed as relative percentage of complexation, where $100 \%$ means pDNA is totally complexed with polymer in NPs, and $0 \%$ means that all pDNA is free (not complexed with the polycation). Polymer solutions with the same polymer concentration were used as control to subtract any polymer background fluorescence.

\subsection{Cellular internalization studies by conventional flow cytometry}

$\mathrm{ND}_{7 / 23}$ (mouse neuroblastoma ( $\left.\mathrm{N}_{18} \operatorname{tg} 2\right) \times$ rat dorsal root ganglion neuron hybrid), $\mathrm{NIH}_{3} \mathrm{~T}_{3}$ (mouse embryonic fibroblast) and RN22 (rat schwannoma) cells (all obtained from ECACC) were seeded into 24-well tissue culture polystyrene (TCPS) plates (Greiner Bio-One, Austria) at a cell density of $4 \times 104$, $5 \times 104$ and $3 \times 104$ viable cells per $\mathrm{cm}_{2}$, respectively. All cells were cultured in DMEM medium with Glutamax supplemented as described above, $24 \mathrm{~h}$ prior incubation with NPs. pDNA was labelled with YOYO $^{{ }_{-1}}$ (Invitrogen, USA) as indicated by the manufacturer. Tg and nT NPs were prepared at different N/P ratios ( 2 to 12) using $2 \mu \mathrm{g}$ of pDNA per $\mathrm{cm} 2$ and incubated with cells for $2 \mathrm{~h}$, at $37^{\circ} \mathrm{C}$. After the incubation period, cells were thoroughly washed with cold phosphate buffered saline (PBS) to stop the internalization process and incubated with $0.4 \%$ (w/v) Trypan Blue ${ }^{\circledR}$ for 10 min to quench any extracellular fluorescence signal. Afterwards, cells were washed and then processed for being

\section{,}


examined by flow cytometry using a FACS Calibur ${ }^{\mathrm{TM}}$ flow cytometer (BD Biosciences, USA). A total of 20,000 gated events were collected for each condition. The resulting data was analyzed using FlowJo ${ }^{\circledR}$ software (version 10, FLOWJO, LLC). Untreated cells were used as negative control.

\subsection{Cellular internalization studies by imaging flow cytometry}

$\mathrm{ND} 7 / 23, \mathrm{NIH}_{3} \mathrm{~T}_{3}$ and $\mathrm{RN} 22$ cells were seeded into 12 -well TCPS plates (Greiner Bio-One, Austria) at a cell density of $4 \times 104,5 \times 104$ and $3 \times 104$ viable cells per $\mathrm{cm} 2$, respectively, 24 h prior incubation with NPs. pDNA was labelled with YOYO ${ }^{\circledR}-1$ (Invitrogen, USA) as indicated by the manufacturer. Neuron-targeted NPs were prepared at N/P ratio of 8 with $2 \mu \mathrm{g}$ of pDNA per $\mathrm{cm} 2$ and incubated with cells for $2 \mathrm{~h}$, at $37^{\circ} \mathrm{C}$.

Afterwards, cells were trypsinized, fixed with $4 \%(\mathrm{w} / \mathrm{v})$ paraformaldehyde in PBS and centrifuged to obtain a pellet of about 105 cells in $50 \mu \mathrm{l}$. Cell images were acquired using an ImageStreamX multispectral imaging flow cytometer (Amnis Corporation - Millipore, Germany), collecting 10,000 events per sample at $40 x$ magnification. A $488 \mathrm{~nm}$ wavelength laser was used to excite YOYO ${ }^{\circledR}-1$. The fluorescence images were collected using the $480-560 \mathrm{~nm}$ spectral detection channel. Cell images were analyzed using IDEAS ${ }^{\circledR}$ image-analysis software version 6.0 (Amnis Corporation Millipore, Germany). Cells within the focal plane were first selected using a two-dimensional plot of image contrast versus root-mean-squared (rms) gradient. Gating on bivariate plot of aspect ratio versus cell area was further used to isolate a population of single cells.

To discriminate NPs inside cells from the ones associated to the cell membrane, cellular masks were created to separate two regions of the cells - internal (cytoplasm) and external (membrane), as previously described [12]. The number of nanoparticle-loaded vesicles (NLV) per cell was determined by using images acquired using the Extended Depth of Field (EDF) filter [22]. To determine the number of NLV per cell, a mask was created in order to identify the fluorescence intensity peaks at least 4 -fold greater than the background. The number of individual vesicles in a cell was enumerated using the Spot Count feature from IDEAS ${ }^{\circledR}$ image-analysis software version 6.o (Amnis, EDM Millipore, Germany), and plotted in frequency histograms.

\subsection{Transfection studies}

ND7/23, $\mathrm{NIH}_{3} \mathrm{~T}_{3}$ and $\mathrm{RN} 22$ cells were seeded into 24-well TCPS plates (Greiner Bio-One, Austria) at a cell density of $4 \times 104,5 \times 104$ and $3 \times 104$ viable cells per $\mathrm{cm} 2$, respectively, $24 \mathrm{~h}$ prior incubation with NPs (using $2 \mu \mathrm{g}$ of pDNA per well $\mathrm{cm} 2$ ). Cell medium was refreshed prior addition of the NPs. $24 \mathrm{~h}$ post-transfection the cell media was removed, and $0.5 \mathrm{ml}$ of fresh complete DMEM medium was added to each well. Cells were incubated for an additional $48 \mathrm{~h}$ period, with daily renewing of the culture media. At $72 \mathrm{~h}$ post-incubation, cells were trypsinized and processed for flow cytometry for eGFP expression determination. Twenty thousand gated events were taken for each replicate and analyzed as described above. Untreated cells were used as negative control.

\subsection{Nanoparticle cytotoxicity}

To determine cell viability, a resazurin-based assay was used [23]. Briefly, $72 \mathrm{~h}$ after incubation with NPs (using $2 \mu \mathrm{g}$ of pDNA per well $\mathrm{cm} 2$ ), a sterile $0.1 \mathrm{mg} . \mathrm{ml}-1$ solution of resazurin (Sigma-Aldrich, USA) in PBS was added to each well to a final $10 \%(\mathrm{v} / \mathrm{v})$ concentration. After 4 h of incubation at $37^{\circ} \mathrm{C}$, 
$200 \mu \mathrm{l}$ of medium was transferred to a black-walled 96-well plate (Greiner Bio-One, Austria) and fluorescence was measured $(\lambda e x c=530 \mathrm{~nm}, \lambda e m=590 \mathrm{~nm})$. Results are expressed as percentage of metabolic activity of treated cells relative to untreated cells.

\subsection{Statistical analysis}

Statistical analysis was performed using GraphPad Prism 7.0. Results are presented as mean \pm standard deviation (SD) of at least two independent experiments, each one with three technical replicates. The D'Agostino-Pearson omnibus test was used to confirm the Gaussian distribution of data. Afterwards, the appropriate statistical test was used, as mentioned in each figure. Results were considered statistically significant when $p<0.05$.

\section{Results}

\subsection{Assessment of the PEGylation density impact on nanoparticle physicochemical properties}

TMC-based NPs were prepared at different N/P ratios and functionalized with different densities ( 1 , 2 or $4 \mathrm{~mol} \%$ of the primary amino groups in the polymer) of either HC-PEG $5 \mathrm{k}$ (Tg NPs) or methoxyPEG5k (MeO-PEG5k; nT NPs) (Scheme 2). The theoretical quantity of PEG per NP refer to the charged PEG per number of moles of primary amine groups (in mol\%) of the total polymer present in each N/P ratio. The coupling efficiency of HC-PEG $5 k$ to the NPs was very high ( $\geq 95.5 \%$ for all grafting densities) as confirmed by SEC analysis of the NP supernatants (see Section 2.6 .2 for experimental details and Supplementary Table S1).

All prepared NPs presented a pDNA condensation efficiency between 85 and 90\% (data not shown). Fig. 1 summarizes the physicochemical characteristics of $\mathrm{Tg}$ and $\mathrm{nT}$ NPs functionalized at different densities with the respective PEG (data from the characterization of the NPs core - without further functionalization - can be found in the Supplementary Table S2).

All formulations presented unimodal size distribution by dynamic light scattering (DLS) (data not shown). As illustrated in Fig. 1a, for both formulations, the higher the degree of PEGylation, the smaller the NPs average diameter size, independently of the N/P ratio tested. Among all, NPs bearing 4 mol\% of PEG (with or without HC) were the ones with the smallest sizes ( $\sim 170$ to $190 \mathrm{~nm}$ ) $(\mathrm{p}<0.01$ when compared to 1 mol\% NPs). Also, the NPs prepared at N/P ratio of 2, particularly those with lower PEGylation densities ( 1 and 2 mol\%), exhibited statistical significant higher average sizes $(p<0.05)$. Above this N/P ratio (N/P > 2), the NPs size did not increase significantly with the N/P ratio, which means that the size is not significantly altered by the increment in the polymer mass and respective percentage of PEGylation. Moreover, no significant differences were found in the mean diameter size between $\mathrm{nT}$ and Tg NPs, showing that HC functionalization does not influence the NP average hydrodynamic sizes.

In contrast, higher N/P ratios led to a concomitant raise in the Pdl values, for all formulations tested (Fig. 1b). Moreover, Tg NPs presented significantly higher PdI values $(p<0.05)$ when compared to the nT NPs, independently of the ligand density at the surface of the NPs. The higher variability can be the consequence of the protein fragment grafting, which may not be incorporated always at the same 
orientation onto the NPs surface. Regardless, all formulations tested presented PdI values below 0.3 , which is within the range of commonly Pdl values obtained for chitosan-based NPs [24].

The surface charge of the developed NPs was also evaluated. As expected, higher degrees of PEGylation led to lower zeta-potential values (Fig. 1C), independently of the presence of $\mathrm{HC}(\mathrm{p}<0.01$ comparing 1 with 4 mol\% NPs at all N/P ratios tested; $p<0.05$ when comparing the grafting densities of 1 with 2 mol\% or 2 with 4 mol\%). For each percentage of PEG functionalization (with or without $H C$ ), no significant differences were found from NPs prepared at different N/P ratios (from 2 to 12 ). Moreover, all prepared NPs presented a cationic surface charge (from +8 to $+14 \mathrm{mV}$ ) indicating a good colloidal stability.

\subsection{Determination of optimal HC-PEG5k density for cell-specific internalization and transfection efficiency}

The effect of HC-PEG 5 k density on the NPs ability to be internalized by cells was studied by flow cytometry on ND7/23 (neuron-like cell line), $\mathrm{NIH}_{3} \mathrm{~T}_{3}$ (fibroblasts) and RN22 (Schwann cell line) cells. The results obtained after a $2 \mathrm{~h}$ incubation period of the cells with formulations prepared at different $\mathrm{N} / \mathrm{P}$ ratios and ligand grafting densities are presented in Fig. $2 \mathrm{a}$, where the distribution of the intensity of YOYO ${ }^{\circledR}$-1-labelled pDNA per cell is reported for each cell line tested (for the data regarding the percentage of $\mathrm{YOYO}^{\circledR}{ }_{-1}^{-1}$ positive cells after NP incubation please refer to the Supplementary Table S3). For the nT NPs, a clear inverse trend is observed between the amount of PEG grafted into NPs and the cellular pDNA intensity $(p<0.05$, when comparing all formulations -1 to $4 \mathrm{~mol} \%$ of PEGylation). This trend seems to be independent of the NPs N/P ratio or the cell line under testing. In the case of the Tg NPs, there is an evident difference between the pDNA intensity in neuronal versus non-neuronal cell lines. In the neuronal cells, a higher accumulation of pDNA per cell is observed as the N/P ratio increases that plateaus at N/P ratio 8.

Contrary to the observed trend in the case of nT NPs, in the case of the Tg formulations we observed that the higher ligand grafting densities are the ones that result in higher cellular uptake efficiencies in neuronal cells, independently of the N/P ratio $(p<0.01)$. Moreover, one can notice that the Tg NPs prepared at N/P ratio of 8 yielded the higher pDNA cellular uptake in the neuronal cell line with the lowest internalization in the fibroblasts and Schwann cells and therefore, this formulation represents a good candidate to maximize the neuronal targeted vectoring capacity of the proposed NPs. Also, the amount of $\mathrm{YOYO}^{\circledR}{ }_{-1}$ positive cells obtained after incubation with the $\mathrm{Tg}$ formulation is always higher than the one obtained when using non-functionalized NPs (control NP core; Supplementary Table S4), independently of the grafting density or NP N/P ratio, which confirms the selectivity of the ligand-receptor pair.

Based on the above, we moved to analyze the effect of the HC-PEG5k density on the transfection efficiency of TMC-based NPs prepared at the N/P ratio of 8 (Fig. 2 b). The ability of TMC-based NPs to transfect ND7/23 cells was previous analyzed by us, where a maximum of $23 \%$ of the cell population expressing the reporter gene was obtained [12]. Regarding the functionalized NPs, a similar trend was obtained for the nT NPs, corroborating the data acquired from the flow cytometry study (Fig. 2a), where higher PEG5k grafting densities led to a reduced percentage of transfected cells. The observed difference was identical to all cell lines tested, with a reduction of approximately 2 -fold in the transfection efficiency from 1 to 4 mol\% in nT NPs $(p<0.05)$. The Tg NPs presented a similar trend when incubated with the non-neuronal cell lines ( $\mathrm{NIH}_{3} \mathrm{~T}_{3}$ and $\mathrm{RN} 22$ ), although not as pronounced 
$(p>0.05)$. Indeed, no statistical differences were found between the transfection efficiencies of $\mathrm{nT}$ versus $\mathrm{Tg}$ formulations at compared grafting densities in the non-neuronal cell lines. In contrast, when incubated with the neuronal cells (ND/23), a distinct tendency was observed for the Tg NPs.

While the incubation with NPs bearing 1 mol\% of HC-PEG5k resulted in a lower percentage of transfected cells $(\sim 15 \%)$ when compared to their equivalent nT NPs, at the grafting density of 2 mol\% HC-PEG5k this percentage was significantly improved to approximately $40 \%$ of the total cell population $(p<0.01)$. The higher grafting density $(4 \mathrm{~mol} \%)$ exhibited an intermediate capacity of transfection, with $\sim 26 \%$ of transfected cells $(p<0.05)$.

\subsection{Preparation of targeted NPs with hetero PEG brushes}

To investigate the effect of PEG spacer length on ligand exposure towards achieving maximum targeting performance, we next compared Tg NPs functionalized with single length HC-PEG5K (Scheme 3a) with NPs prepared using a PEGylation "cocktail" that consisted of mixed ratios of PEG spacers of different length (Scheme $3 \mathrm{~b}$ ). For this, shorter PEG molecules (MeO-PEG2k) were tethered to NPs along with HC-bound longer PEGs (HC-PEG5k).

For the subsequent analysis, all NPs were prepared at the same N/P ratio (N/P = 8) and using the same grafting density of 2 mol\% of TMC primary amine groups, as this was previously shown to be the one mediating the best biological performance (neuronal targeting and transfection).

The SEC analysis of the NP supernatants (see Section 2.6.2 for experimental details and Supplementary Table $\mathrm{S}_{5}$ ) revealed that the coupling efficiency of HC-PEG $5 \mathrm{k}$ to the NP surface ranged between $\sim 90 \%$ and $92 \%$, while the coupling efficiency of MeO-PEG $2 k$ was $\geq 98 \%$ for all cases.

The results from the physicochemical characterization of the produced NPs are presented in Table 1. As can be observed, no differences were found in terms of average size, Pdl or zeta potential values among all tested formulations ( $p>0.05$ ). This is not a surprising result, as the N/P ratio and grafting density, two major contributors for NPs physicochemical properties, were not altered between formulations.

\subsection{Evaluation of internalization and payload delivery of neuron- targeted NPs functionalized with hetero PEG brushes}

Subsequently, we evaluated the performance of the different NP formulations in terms of internalization and payload delivery to the three cell lines under testing. Although by conventional flow cytometry, no differences could be observed in terms of internalization between all targeted formulations (NPs prepared at the same N/P ratio and ligand grafting densities, bearing different molar ratios of HC-PEG5k:PEG 2 ; Supplementary Table S6), when performing the internalization study exploring imaging flow cytometry we could find significant differences in the behavior of the tested NPs. The use of this technique allowed us to clearly distinguish between internalized (Fig. 3a) versus membrane-bound NPs (Fig. 3b) [12], [25]. In this particular case, where we are evaluating the importance of very precise NP design on the overall transfection process, the use of this advanced bioimaging technique was of paramount importance. 
As depicted in Fig. 3C, a statistical significant difference was found in the percentage of neuronal cells that had internalized NPs $(>72 \%)$, compared to the non-neuronal cells $(<26 \%)(p<0.001)$. This result indicates that these NPs are being preferentially internalized by the neuronal population, corroborating the previous data obtained by conventional flow cytometry (Fig. 2a). When comparing the internalization efficiency in neuronal cells among the different tested formulations, no significant differences were found, with exception for the comparison between Tg1:1 and Tg1:2 NPs $(p<0.05)$, having the latter a poor performance in contrast with the former. Moreover, Tg1:2 NPs were also more internalized in the non-neuronal cells when in comparison to $\mathrm{Tg} 1: 1$.

As no major differences were found between the different NP formulations in terms of internalization efficiency, we next evaluated the payload delivery efficiency into neuronal cells. For this, we used another feature of the imaging flow cytometry analysis software (IDEAS ${ }^{\circledR}$, Amnis Corporation, Germany) to assess the number of nanoparticle-loaded vesicles (NLV) per cell (Fig. 3d), a methodology previously described by us [12]. By quantifying the number of NP clusters within individual vesicles (endosomes or lysosomes), one can infer about the efficiency of each formulation to delivery their payload into cells, through the determination of the intracellular distribution of NLVs.

Three groups with low $(\leq 4)$, medium $(>4$ and $\leq 9$ ) or high $(\geq 10)$ number of NLV per cell were gated among the cells that had internalized NPs (Fig. 3e). The results clearly show that the Tg1:1 NPs were the ones with the best performance among all formulations, with $\sim 60 \%$ of the cell population having 10 or more NLVs per cell, and only 13\% of cells with low number of NLVs. The Tg and Tg2:1 NPs presented similar performances, with the majority of the population having a medium number of NLVs, and less than $30 \%$ of cells with 10 or more NLVs. As observed in the internalization data, the Tg1:2 NPs were the ones that not only internalized in a lower percentage of cells but also that presented the lower amount of payload delivery, since the bulk population that internalized these particles $(\sim 50 \%)$ presented a maximum of $4 \mathrm{NLVs}$ per cell. Altogether, these results indicate that, despite the similarities found in terms of internalization efficiency, the Tg1:1 NPs were able to deliver a higher payload amount to cells, leading to the presence of a higher concentration and accumulation of pDNA.

\subsection{Transfection efficiency of neuron-targeted NPs functionalized with hetero PEG brushes}

The transfection mediated by neuron-targeted NPs prepared with mixed ratios of different length PEG spacers (N/P ratio of 8 and PEG grafting density ratio of 2 mol\% per primary amine group) was assessed. The different cell lines under study were incubated for $24 \mathrm{~h}$ with the prepared formulations and the transfection efficiency assessed $48 \mathrm{~h}$ post-incubation by quantifying the number of positive cells for eGFP by flow cytometry. The results (Fig. 4) show a marked difference in the number of eGFP positive cells when NPs were incubated with neuronal (ND7/23) or non-neuronal cells $\left(\mathrm{NIH}_{3} \mathrm{~T}_{3}\right.$ and RN22). All formulations presented a similar behavior when incubated with non-neuronal cells, with a maximum of $11 \%$ of the total population being transfected in the case of Tg1: 2 NPs. In contrast, the percentage of neuronal cells being transfected was significantly higher than the non-neuronal cells $(p<0.001)$. Among the neuronal population, the formulation that achieved the highest percentage of transfected cells was the Tg1:1 NPs, leading to the expression of eGFP in more than half of the cell population $(\sim 53 \%$ of transfected cells; $\mathrm{p}<0.01)$. These results are in accordance with the previous 
findings observed in imaging flow cytometry, as these NPs revealed to be the most efficient to deliver their payload into neuronal cells.

To exclude the possibility of any interference related to cell viability in the transfection results, we also evaluated the metabolic activity of these cells after incubation with all formulations under testing (Supplementary Fig. S2). The results showed that none of these formulations presented a significant cytotoxic effect in the different cell types tested.

\section{Discussion}

For more than two decades PEG has been the polymer of choice for surface modification of particulate drug/gene carriers to provide improved pharmacological properties and to allow for the preparation of targeted delivery systems [26]. The PEG layer may have different roles in a particle biological fate, and all of them depend on its surface grafting density. PEG coatings are known to prevent aggregation and to stabilize NPs in media with physiological salt concentration by steric and hydration repulsions [26]. The resistance to non-specific absorption of plasmatic proteins is one of the most important determinant of NP fate once administered in the host [27]. High resistance to protein adsorption leads to a decreased uptake by the mononuclear phagocytose system, decreased degradation and elimination rate leading to a longer half-life in the extracellular compartments, which in turn influences NPs pharmacokinetic parameters. Resistance to protein adsorption may also improve targeting capabilities by preventing obstruction by steric hindrance of ligand recognition [28], [29]. The PEG layer present on NP surfaces can also improve drug or nucleic acids encapsulation by providing a physicochemical barrier to payload escape, and it might additionally affect drug/nucleic acid release pattern [30]. On the other hand, excessive PEGylation degrees can lead to a strong inhibition of cellular uptake and to a less efficient interaction and binding with target receptors, as target recognition of ligand molecules located at the surface of a PEGylated NP are also dependent on the density and thickness of the PEG layer and the positioning of the ligand [26].

Taking this into account, in this work we aimed to determine the optimal PEG grafting density and ligand exposure at the surface of TMC-based NPs, in order to achieve maximum vectoring capacity towards neuronal cells. After establishing the grafting density, we further investigated the effect of the PEG chain organization on the ligand exposure at the neuron-targeted NPs surface by testing mixed ratios of a HC-tethered PEG (HC-PEG5k) and a short free PEG chain of $2 \mathrm{kDa}$ (MeO-PEG2k).

Initially, we evaluated the effect of the HC-PEG5k grafting density on the NPs physicochemical properties, such as size and zeta potential. Our data indicate that the increase in PEG grafting density is inversely correlated to NPs size, as with increasing PEGylation a reduction in the NPs dimensions was observed. A similar behavior was previously reported for similar PEG lengths in other polymeric NPs [31], [32], [33], [34], [35]. This result can be explained considering that the structure of the PEG layer is strongly influenced by the chain length. Specifically, it has been suggested that longer chain PEGs (such as $5 \mathrm{kDa}$ ) interact via short-range van der Waals attraction and inter-chain hydrogen bonding, producing chain entanglement, that results in a condensation of the size of the outer layer that will, ultimately, lead to NPs with smaller hydrodynamic size [36]. The increase in PEG density also prompted a decrease in zeta potential. As this has been observed independently of the N/P ratios tested, it can be inferred that this effect arises from the spatial shielding of the polymer positive surface charges by the PEG chains. 
Subsequently, we determined the percentage of HC-PEG grafting density that mediated higher internalization into neuronal cells. The amount of cellular uptake was monitored by flow cytometry using YOYO ${ }^{\circledR}-1$ labelled pDNA. Our data revealed that the highest uptake was obtained for NPs with a N/P ratio of 8 and higher grafting densities ( 2 and 4 mol\% of primary amines in the polymer). In contrast, for nT NPs, increasing the PEG density consistently reduced the uptake efficiency, as described by others [8]. This data is in accordance with previous findings reported by us, where we observed the preferentially binding of $\mathrm{HC}$-functionalized NPs towards neuronal populations in biological models of different complexity [13], and their more efficient retrograde transport towards the neuronal cell body [14]. Therefore, we have confidence that the higher payload delivery obtained from the incubation of $\mathrm{Tg} N \mathrm{~N} s$ with neuronal cells results from the receptor-mediated internalization promoted by the interaction between $\mathrm{HC}$ and the ganglioside receptors present in this neuronal cell line.

When considering a PEGylated NP, it is believed that the PEG will extend away from the particle. However, as deGennes proposed, there are two regimens for polymers attached to a surface, depending on their grafting density [37] - if the density is too low, the polymer is said to be in a "mushroom-like" conformation, where the PEG chains will bend toward the surface; on the contrary, if the grafting density is high enough, the polymers are said to be in the "brush-like" regimen, and the PEG molecules will be extended away from the surface (Scheme 4). The molecular weight of the polymer, as well as its grafting density will determine the degree of surface coverage and distance between graft sites [37], [38], and will ultimately affect the exposure of the targeting moiety and the NPs targeting efficiency. In addition, following cellular binding and internalization, NPs need to efficiently release their payload into the cytoplasm. This critical step is dependent on several parameters such as the endosomal protonation of chitosan, which will promote the entry of counter ions into the endosome, increasing ionic concentration and hence water influx that will contribute to endosomal rupture (proton sponge effect) [39], [40], the ability of the polymer to unfold from a collapsed state into an extended conformation after protonation of the amine groups (umbrella effect) [41] and its biodegradation rate [12]. All these outcomes are influenced by the degree of PEGylation.

From our data, it seems that for these TMC-based NPs an intermediate PEG grafting density of $2 \mathrm{~mol} \%$ is ideal to promote the best PEG conformation in order to better expose the $\mathrm{HC}$ fragment at the surface, resulting in the right balance between NP stability and receptor-mediated internalization, and consequently, transfection efficiency.

Having determined the best ligand density for cellular uptake and transfection efficiency, we next investigated how to enhance HC exposure and motion at the NPs surface to achieve the best biological performance and specificity towards neuronal cells. The ability of the targeting moiety to present free motion at the nanocarrier surface is of critical importance for optimal active targeting. If grafted at a high density, the PEG molecules could reduce the ligand motility and freedom of association to its receptor, due to the steric repulsive (or crowding) effect derived from neighboring PEG chains [42] (Scheme 4).

To overcome this hurdle, we generated NPs containing hetero PEG brushes by using a longer HClinker PEG ( $5 \mathrm{kDa}$ ) and a free shorter PEG ( $2 \mathrm{kDa}$ ) as a filler molecule, at different mixed molar ratios. All the produced NPs presented similar physicochemical properties, as their N/P ratio and PEG grafting densities were kept constant. 
Afterwards, their target towards neuron-like cells was systematically evaluated in terms of internalization and payload delivery efficiency through imaging flow cytometry. The obtained data revealed the Tg1:1 NPs as the formulation with the best biological performance in terms of payload delivery into target cells, as well as transfection efficiency. Moreover, this formulation performed even better than the formulation with $100 \%$ of $\mathrm{HC}-\mathrm{PEG} 5 \mathrm{k}$, which present the double amount of HC protein functionalized into NPs. These results suggest that the filling effect of shorter PEG chains is more critical for the right ligand exposure and consequent binding ability of these NPs than the fed amount of ligand-installed PEG chains, which can be explained by considering that the binding ability of ligand functionalized NPs is determined by the number of receptor-accessible ligand molecules, as previously shown in a pilot study by Ishii et al. [17].

Altogether, the results herein reported suggest that the mobility of ligands, as well as their density, are crucial for the multivalent binding ability of ligand-functionalized NPs, and thus should be carefully designed according to the desired application.

\section{Conclusions}

In summary, our study showed that the precise adjustment of PEG grafting density and length presented a significant impact on the biological performance of the developed NPs, either in terms of their internalization capacity as their transfection efficiency. This outcome emphasizes the need for the fine-tuning of PEG-modified NPs to attain optimal pDNA specifically delivery and bioactivity, as well as endorse the critical importance for the spatial control of the targeting moieties for the successful development of the next-generation nanomedicines.

\section{Acknowledgements}

The authors would like to acknowledge the Bioimaging Platform (i3S) for the support with imaging flow cytometry, the Biointerfaces Nanotechnology Platform (i3S) for GPC and NP characterization, the Biochemical and Biophysical Technologies Platform (i3S) for SEC, as well as the Centro de Materiais da Universidade do Porto (CEMUP) for NMR analysis. The work was financed by Portuguese funds through FCT (Fundação para a Ciência e a Tecnologia) in the framework of the projects UID/BIM/04293/2013, PTDC/CTM-NAN/115124/2009 and PTDC/CTM-NAN/3547/2014. CP Gomes and CDF Lopes acknowledge FCT for their PhD scholarships (SFRH/BD/79930/2011 and

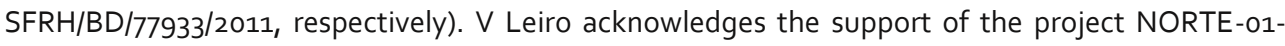
0145-FEDER-000012, financed by Norte Portugal Regional Operational Programme (NORTE 2020), under the PORTUGAL 2020 Partnership Agreement, through the European Regional Development Fund (ERDF). AP Spencer acknowledges the support of the project Fundo para a Investigação em Saúde (INFARMED, project reference FIS-2015-01_CCV_20150630-88). 


\section{REFERENCES}

[1] C.J. Cheng, G.T. Tietjen, J.K. Saucier-Sawyer, W.M. Saltzman, A holistic approach to targeting disease with polymeric nanoparticles, Nat. Rev. Drug Discov. 14 (4) (2015) 239-247.

[2] S. Parveen, R. Misra, S.K. Sahoo, Nanoparticles: a boon to drug delivery, therapeutics, diagnostics and imaging, Nanomedicine 8 (2) (2012) 147-166.

[3] M. Arachchige, Y. Reshetnyak, O. Andreev, Advanced targeted nanomedicine, J. Biotechnol. 202 (2015) 88-97.

[4] N. Kamaly, Z. Xiao, P.M. Valencia, A.F. Radovic-Moreno, O.C. Farokhzad, Targeted polymeric therapeutic nanoparticles: design, development and clinical translation, Chem. Soc. Rev. 41 (7) (2012) 2971-3010.

[5] D. Peer, J.M. Karp, S. Hong, O.C. Farokhzad, R. Margalit, R. Langer, Nanocarriers as an emerging platform for cancer therapy, Nat. Nanotechnol. 2 (12) (2007) 751-760.

[6] J.D. Byrne, T. Betancourt, L. Brannon-Peppas, Active targeting schemes for nanoparticle systems in cancer therapeutics, Adv. Drug Deliv. Rev. 60 (15) (2008) 1615-1626.

[7] J.V. Jokerst, T. Lobovkina, R.N. Zare, S.S. Gambhir, Nanoparticle PEGylation for imaging and therapy, Nanomedicine (Lond.) 6 (4) (2011) 715-728.

[8] S. Mishra, P. Webster, M.E. Davis, PEGylation significantly affects cellular uptake and intracellular trafficking of non-viral gene delivery particles, Eur. J. Cell Biol. 83 (3) (2004) 97-111.

[9] H. Hatakeyama, H. Akita, H. Harashima, A multifunctional envelope type nano device (MEND) for gene delivery to tumours based on the EPR effect: a strategy for overcoming the PEG dilemma, Adv. Drug Deliv. Rev. 63 (3) (2011) 152-160.

[10] S. Hama, S. Itakura, M. Nakai, K. Nakayama, S. Morimoto, S. Suzuki, K. Kogure, Overcoming the polyethylene glycol dilemma via pathological environmentsensitive change of the surface property of nanoparticles for cellular entry, J. Control. Release 206 (2015) 67-74.

[11] C.P. Gomes, C.D. Ferreira Lopes, P.M. Duarte Moreno, A. Varela-Moreira, M.J. Alonso, A.P. Pêgo, Translating chitosan to clinical delivery of nucleic acid-based drugs, MRS Bull. 39 (01) (2014) 60-70.

[12] C.P. Gomes, A. Varela-Moreira, V. Leiro, C.D. Lopes, P.M. Moreno, M. Gomez- Lazaro, A.P. Pêgo, A highthroughput bioimaging study to assess the impact of chitosan-based nanoparticle degradation on DNA delivery performance, Acta Biomater. 46 (2016) 129-140.

[13] C.P. Gomes, C.D.F. Lopes, M. Leitner, A. Ebner, P. Hinterdorfer, A.P. Pêgo, Atomic force microscopy as a tool to assess the specificity of targeted nanoparticles in biological models of high complexity, Adv. Healthcare Mater. 6 (2017) 1700597.

[14] C.D. Lopes, C.P. Gomes, E. Neto, P. Sampaio, P. Aguiar, A.P. Pêgo, Microfluidicbased platform to mimic the in vivo peripheral administration of neurotropic nanoparticles, Nanomedicine (Lond.) 11 (24) (2016) 3205-3221.

[15] C.D. Lopes, N.P. Goncalves, C.P. Gomes, M.J. Saraiva, A.P. Pêgo, BDNF gene delivery mediated by neurontargeted nanoparticles is neuroprotective in peripheral nerve injury, Biomaterials 121 (2017) 83-96.

[16] A. Venuta, F. Moret, G. Dal Poggetto, D. Esposito, A. Fraix, C. Avitabile, F. Ungaro, M. Malinconico, S. Sortino, A. Romanelli, P. Laurienzo, E. Reddi, F. Quaglia, Shedding light on surface exposition of poly(ethylene glycol) and folate targeting units on nanoparticles of poly(e-caprolactone) diblock copolymers: beyond a paradigm, Eur. J. Pharm. Sci. 111 (2018) 177-185.

[17] T. Ishii, K. Miyata, Y. Anraku, M. Naito, Y. Yi, T. Jinbo, S. Takae, Y. Fukusato, M. Hori, K. Osada, K. Kataoka, Enhanced target recognition of nanoparticles by cocktail PEGylation with chains of varying lengths, Chem. Commun. (Camb.) 52 (7) (2016) 1517-1519.

INSTITUTO DE INVESTİGAÇÃO E INOVAÇÃO EM SAÚDE UNIVERSIDADE DO PORTO

Rua Alfredo Allen, 208 4200-135 Porto Portugal +351220408800 
[18] USA Food and Drug Administration, Guidance for Industry - Pyrogen and Endotoxins Testing, 2012.

[19] H. Oliveira, R. Fernandez, L.R. Pires, M.C.L. Martins, S. Simões, M.A. Barbosa, A. P. Pêgo, Targeted gene delivery into peripheral sensorial neurons mediated by self-assembled vectors composed of poly(ethylene imine) and tetanus toxin fragment c, J. Control. Release 143 (3) (2010) 350-358.

[20] K. Sinha, M. Box, G. Lalli, G. Schiavo, H. Schneider, M. Groves, G. Siligardi, N. Fairweather, Analysis of mutants of tetanus toxin $\mathrm{HC}$ fragment: ganglioside binding, cell binding and retrograde axonal transport properties, Mol. Microbiol. 37 (5) (2000) 1041-1051.

[21] H. Oliveira, L.R. Pires, R. Fernandez, M.C.L. Martins, S. Simões, A.P. Pêgo, Chitosan-based gene delivery vectors targeted to the peripheral nervous system, J. Biomed. Mater. Res. Part A 95A (3) (2010) 801-810.

[22] W.E. Ortyn, D.J. Perry, V. Venkatachalam, L. Liang, B.E. Hall, K. Frost, D.A. Basiji, Extended depth of field imaging for high speed cell analysis, Cytometry A 71 (4) (2007) 215-231.

[23] J. O'Brien, I. Wilson, T. Orton, F. Pognan, Investigation of the Alamar Blue (resazurin) fluorescent dye for the assessment of mammalian cell cytotoxicity, Eur. J. Biochem. 267 (17) (2000) 5421-5426.

[24] N. Csaba, M. Koping-Hoggard, M.J. Alonso, lonically crosslinked chitosan/ tripolyphosphate nanoparticles for oligonucleotide and plasmid DNA delivery, Int. J. Pharm. 382 (1-2) (2009) 205-214.

[25] A.M. Silva, A. Varela-Moreira, C. Pereira Gomes, M. Molinos, M. Leite, M. Almeida, D. Ribeiro, M. Schrader, C. Figueiredo, M. Barbosa, R. Goncalves, C. Almeida, A. Pêgo, S.G. Santos, M. Gomez-Lazaro, Integrated analysis of biological samples by imaging flow cytometry, Microsc. Microanal. 21 (Suppl 5) (2015) 95-96.

[26] J.M. Rabanel, P. Hildgen, X. Banquy, Assessment of PEG on polymeric particles surface, a key step in drug carrier translation, J. Control. Release 185 (2014) 71-87.

[27] A.E. Nel, L. Madler, D. Velegol, T. Xia, E.M.V. Hoek, P. Somasundaran, F. Klaessig, V. Castranova, M. Thompson, Understanding biophysicochemical interactions at the nano-bio interface, Nat. Mater. 8 (7) (2009) 543-557.

[28] A. Salvati, A.S. Pitek, M.P. Monopoli, K. Prapainop, F.B. Bombelli, D.R. Hristov, P. M. Kelly, C. Aberg, E. Mahon, K.A. Dawson, Transferrin-functionalized nanoparticles lose their targeting capabilities when a biomolecule corona adsorbs on the surface, Nat. Nanotechnol. 8 (2) (2013) 137-143.

[29] V. Mirshafiee, M. Mahmoudi, K.Y. Lou, J.J. Cheng, M.L. Kraft, Protein corona significantly reduces active targeting yield, Chem. Commun. 49 (25) (2013) 2557-2559.

[30] G. Fontana, M. Licciardi, S. Mansueto, D. Schillaci, G. Giammona, Amoxicillinloaded polyethylcyanoacrylate nanoparticles: influence of PEG coating on the particle size, drug release rate and phagocytic uptake, Biomaterials 22 (21) (2001) 2857-2865.

[31] S. Mao, X. Shuai, F. Unger, M. Wittmar, X. Xie, T. Kissel, Synthesis, characterization and cytotoxicity of poly(ethylene glycol)-graft-trimethyl chitosan block copolymers, Biomaterials 26 (32) (2005) 6343-6356.

[32] K. Kunath, A. von Harpe, H. Petersen, D. Fischer, K. Voigt, T. Kissel, U. Bickel, The structure of PEG-modified poly(ethylene imines) influences biodistribution and pharmacokinetics of their complexes with NF-jB decoy in mice, Pharmaceut. Res. 19 (6) (2002) 810-817.

[33] H. Petersen, P.M. Fechner, A.L. Martin, K. Kunath, S. Stolnik, C.J. Roberts, D. Fischer, M.C. Davies, T. Kissel, Polyethylenimine-graft-poly(ethylene glycol) copolymers: influence of copolymer block structure on DNA complexation and biological activities as gene delivery system, Bioconjug. Chem. 13 (4) (2002) 845-854.

[34] H. Lee, J.H. Jeong, T.G. Park, PEG grafted polylysine with fusogenic peptide for gene delivery: high transfection efficiency with low cytotoxicity, J. Control. Release 79 (1-3) (2002) 283-291. 
[35] A. Gutoaia, L. Schuster, S. Margutti, S. Laufer, B. Schlosshauer, R. Krastev, D. Stoll, H. Hartmann, Fine-tuned PEGylation of chitosan to maintain optimal siRNA-nanoplex bioactivity, Carbohydr. Polym. 143 (2016) 25-34.

[36] D. Pozzi, V. Colapicchioni, G. Caracciolo, S. Piovesana, A.L. Capriotti, S. Palchetti, S. De Grossi, A. Riccioli, H. Amenitsch, A. Lagana, Effect of polyethyleneglycol (PEG) chain length on the bio-nano-interactions between PEGylated lipid nanoparticles and biological fluids: from nanostructure to uptake in cancer cells, Nanoscale 6 (5) (2014) 2782-2792.

[37] P.G. deGennes, Conformations of polymers attached to an interface, Macromolecules 13 (5) (1980) 1069-1075.

[38] C. Allen, N.D. Santos, R. Gallagher, G.N.C. Chiu, Y. Shu, W.M. Li, S.A. Johnstone, A.S. Janoff, L.D. Mayer, M.S. Webb, M.B. Bally, Controlling the physical behavior and biological performance of liposome formulations through use of surface grafted poly(ethylene glycol), Biosci. Rep. 22 (2) (2002) 225-250.

[39] D.W. Pack, A.S. Hoffman, S. Pun, P.S. Stayton, Design and development of polymers for gene delivery, Nat. Rev. Drug Discov. 4 (7) (2005) 581-593.

[40] N.D. Sonawane, F.C. Szoka Jr., A.S. Verkman, Chloride accumulation and swelling in endosomes enhances DNA transfer by polyamine-DNA polyplexes, J. Biol. Chem. 278 (45) (2003) 44826-44831.

[41] H. Ragelle, G. Vandermeulen, V. Preat, Chitosan-based siRNA delivery systems, J. Control. Release 172 (1) (2013) 207-218.

[42] K. Miyata, Smart polymeric nanocarriers for small nucleic acid delivery, Drug Discov. Ther. 10 (5) (2016) 236 247 . 
a

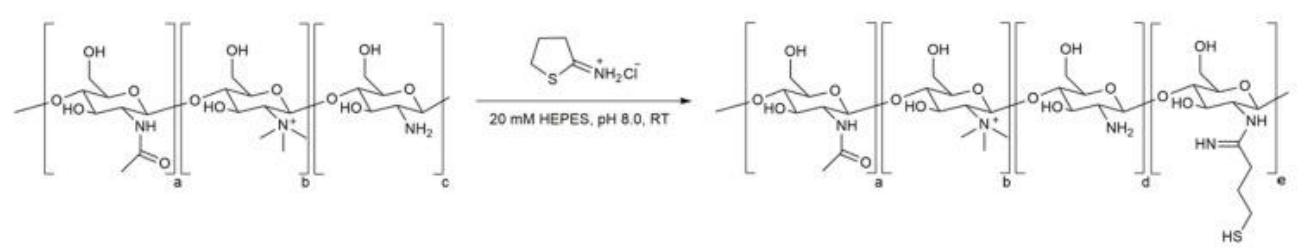

b

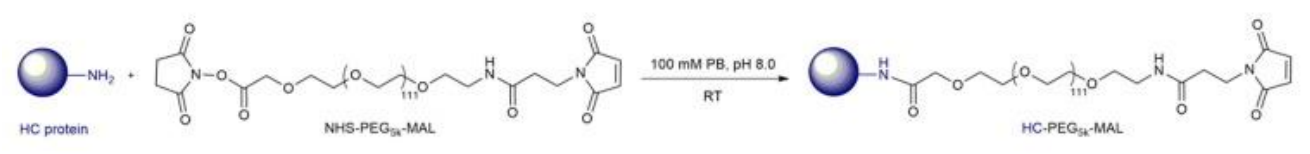

C

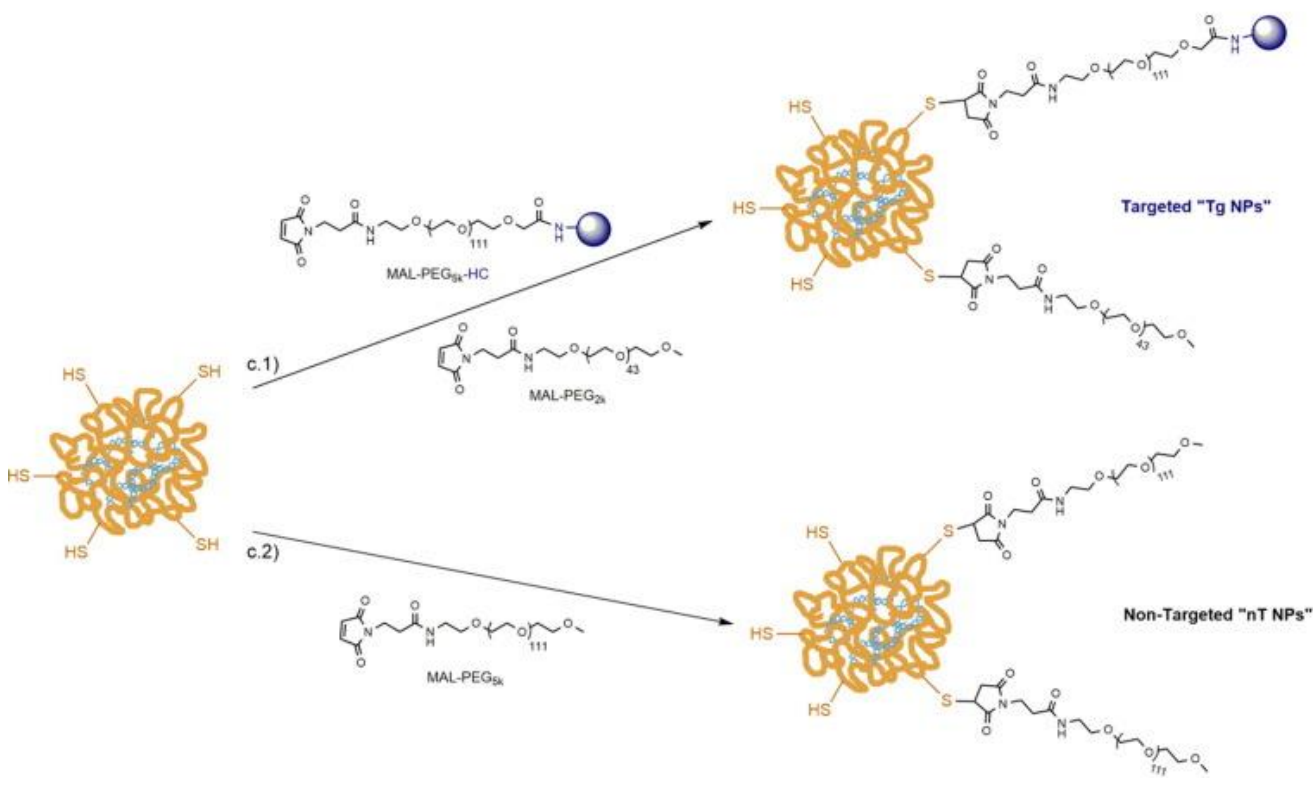

Scheme 1. Illustrative chemical reactions for the preparation of (a) TMCSH, (b) HC-PEG5k and (c) functionalization of TMC-based polyplexes with c.1) HC-PEG5k alone or in conjugation with MeO-PEG $2 \mathrm{k}$ for the preparation of Tg NPs and c.2) MeO-PEG5k for the preparation of nT NPs. Note: illustrative representation not to scale.

Rua Alfredo Allen, 208 4200-135 Porto 
a

Nanoparticle Functionalization

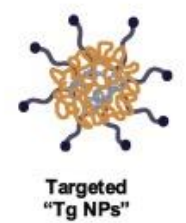

VS
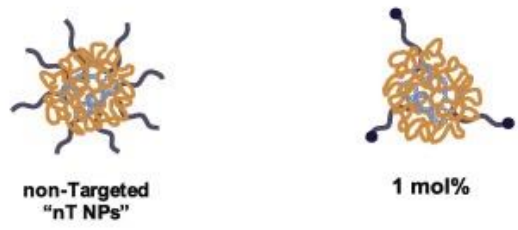

$1 \mathrm{~mol} \%$

Ligand Density Optimization

mol \% of TMC primary amines substitution

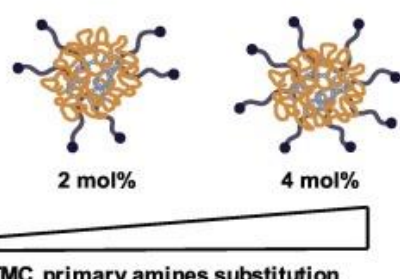

- HC Fragment

Scheme 2. Schematic representation of the functionalization of TMC-based nanoparticles. a) TMC-based NPs were functionalized either with $\mathrm{HC}$ coupled to a $5 \mathrm{kDa}$ heterobifunctional PEG spacer ( $\mathrm{N}$-hydroxysuccinimidePEG-maleimide; HC-PEG $5 \mathrm{k}$ ) to produce neuron-targeted NPs (Tg NPs) or with the 5 kDa methoxy-PEG-maleimide (MeO-PEG5k) spacer (non-Targeted NPs; nT NPs). b) The prepared NPs were functionalized with increasing amounts of $\mathrm{HC}_{-} \mathrm{PEG}_{5} \mathrm{k}$ or MeO-PEG $5 \mathrm{k}$, with the charged amount of PEG per NP being shown below each formulation. Note: illustrative representation not to scale.

a
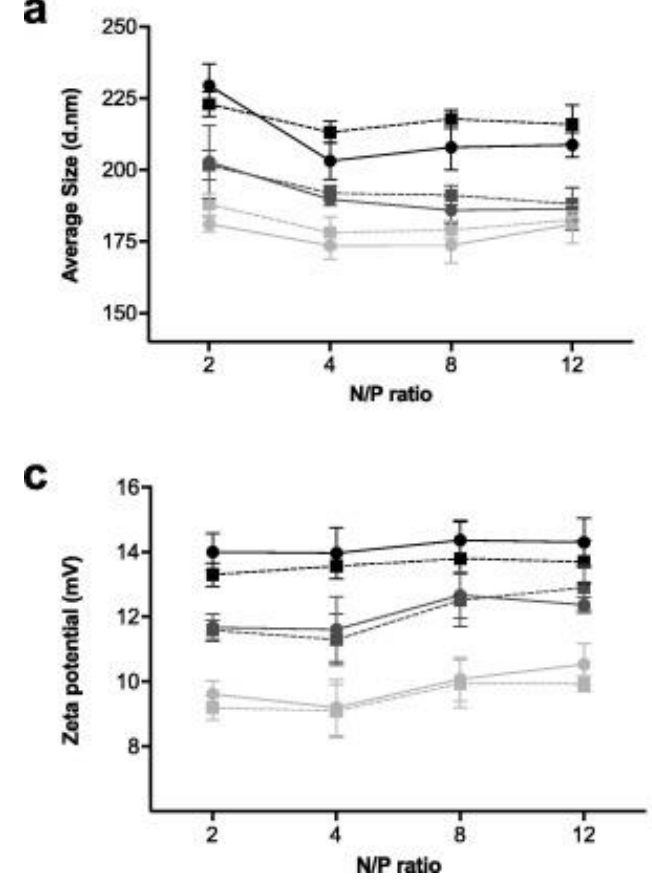

b

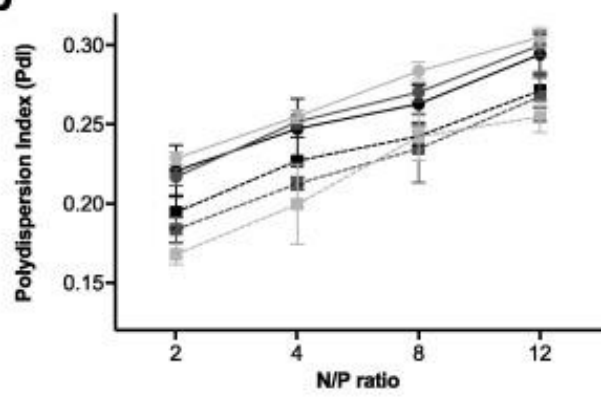

Legend:

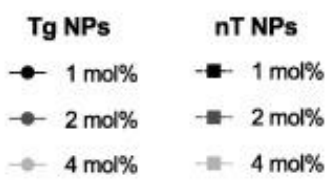

Fig. 1. Physicochemical characterization of functionalized TMC NPs as a function of N/P ratio and PEG density. TMC-based NPs prepared at different N/P ratios were functionalized with increasing amounts of HC-PEG $5 \mathrm{k}$ (Tg NPs) or MeO-PEG5k (nT NPs). a) Average hydrodynamic sizes, b) polydispersity index and c) zeta potential were measured by dynamic light scattering in PBS, $\mathrm{pH} 7.4$ at $25^{\circ} \mathrm{C}$. Results from three independent experiments are 
represented as mean \pm SD. Statistical differences between $\mathrm{Tg}$ and $\mathrm{nTNPs}$ were assessed through the multiple $\mathrm{t}$ test analysis.

a

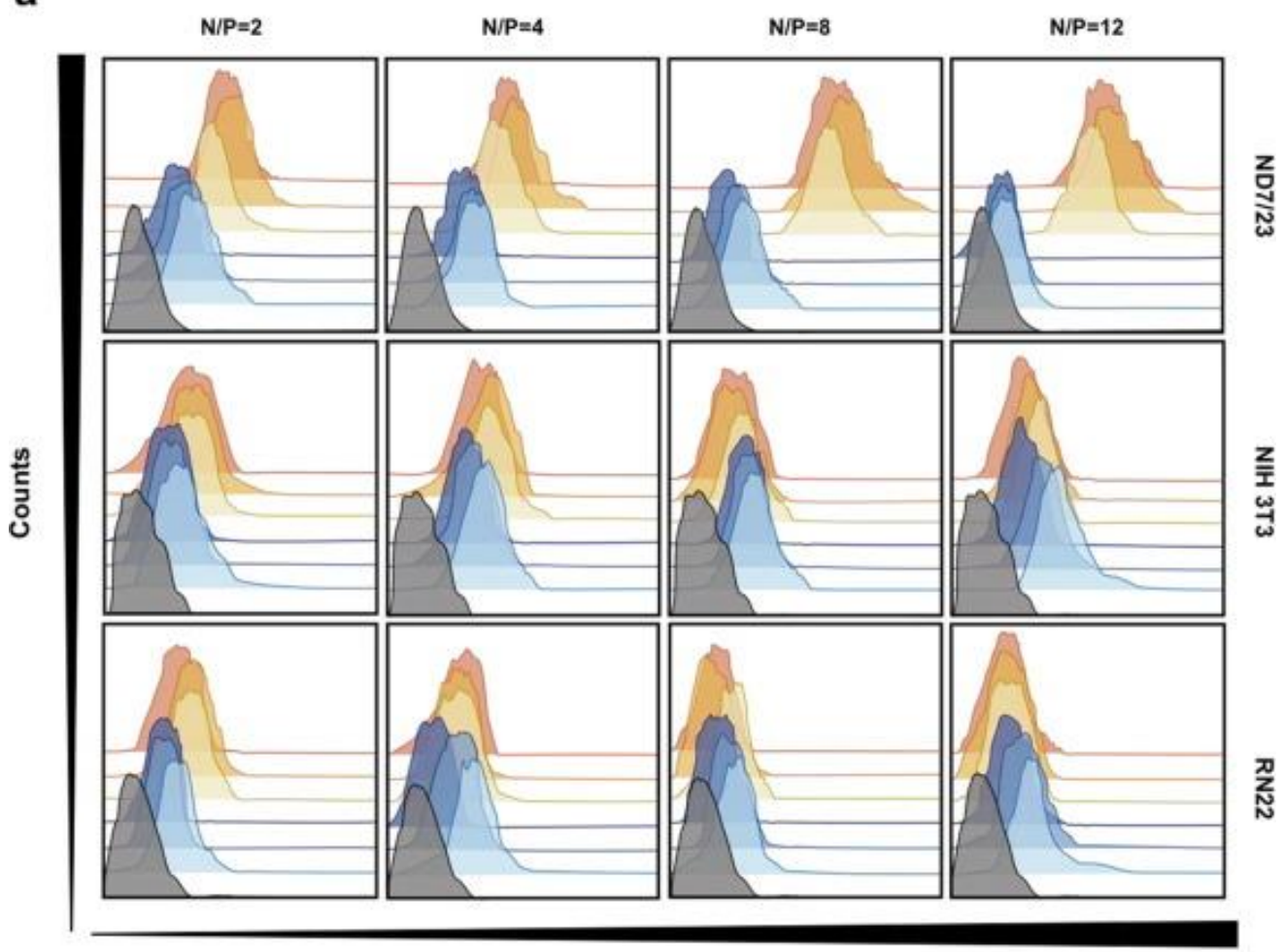

Cell fluorescence intensity (YOYO®-1)

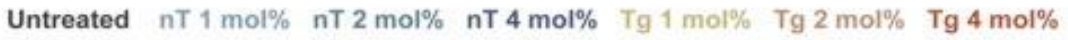

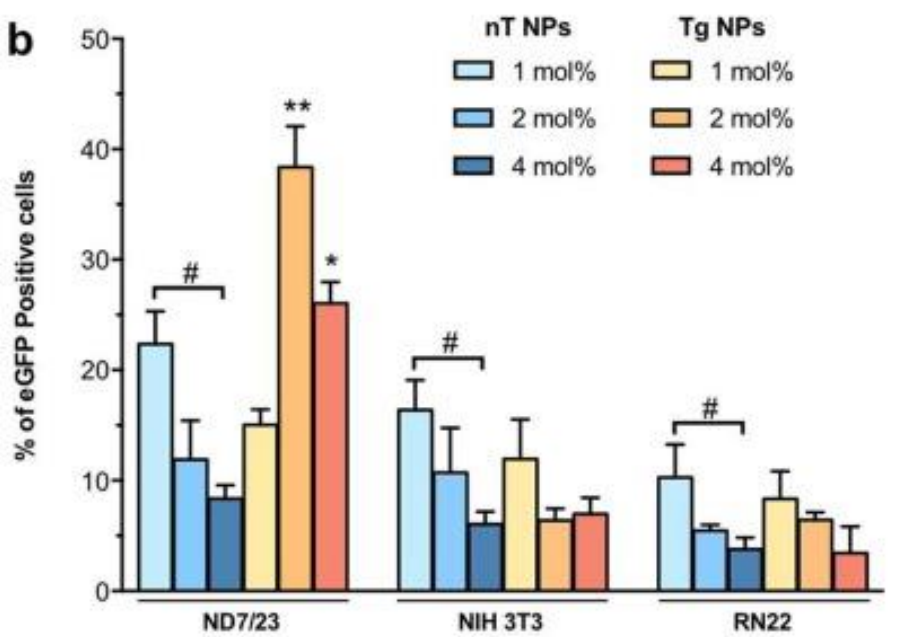

Fig. 2. Extent of cellular uptake and transfection efficiency of Targeted (Tg) versus non-Targeted (nT) TMC NPs. a) Cellular uptake: representative flow cytometry distributions showing the intensity of pDNA fluorescence among 
$\mathrm{ND}_{7} / 23, \mathrm{NIH}_{3} \mathrm{~T}_{3}$ and $\mathrm{RN}_{22}$ cells after a $2 \mathrm{~h}$ incubation with TMC-based NPs prepared with labelled (YOYO ${ }^{{ }_{-1}}$ ) pDNA at different N/P ratios; untreated cells were used as control. b) Transfection efficiency: the percentage of viable cells expressing eGFP was analyzed by flow cytometry $72 \mathrm{~h}$ post-incubation with the different formulations; untreated cells were used as control. Each bar represents the mean of three independent experiments \pm SD. Statistical differences were assessed through the multiple $t$ test analysis and are represented as: ${ }^{*} p<0.05$ and $* * p<0.01$ for comparisons among Tg NPs; \#p $<0.05$ for comparisons among nT NPs; no symbol $=p>0.05$. (For better interpretation of the color legends in this figure, the reader is referred to the web version of this article).

a

\section{Single length PEG spacer}

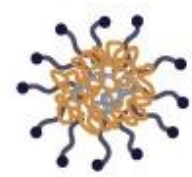

Tg NPs

(100\% HC-PEG $\left._{5 \mathrm{sk}}\right)$ b

Mixed PEG spacers

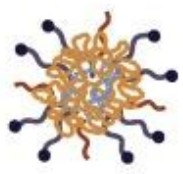

$\mathrm{Tg}_{2: 1}$ NPs

(2 HC-PEG $_{5 \mathrm{k}}$ : $1 \mathrm{PEG}_{2 \mathrm{k}}$ )

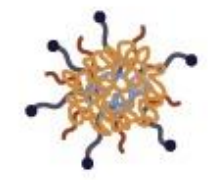

$\mathrm{Tg}_{1: 1}$ NPs

(1 HC-PEG 5 : 1 PEG ${ }_{2 k}$ )

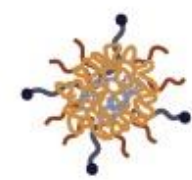

$\operatorname{Tg}_{1: 2}$ NPs

(1 $\mathrm{HC}^{-} \mathrm{PEG}_{5 \mathrm{k}}: 2 \mathrm{PEG}_{2 \mathrm{k}}$ )

\section{Legend:}

HC coupled to $5 \mathrm{kDa}$ NHS-PEG-MAL (HC-PEG (5k $_{\mathrm{k}}$ )

2 kDAMEO-PEG-MAL (PEG

Scheme 3. Schematic representation of the preparation of functionalized hetero PEG-neuron-targeted TMC NPs. To optimize the exposition of HC at the NPs surface, TMC NPs were prepared at the N/P ratio of 8 using 2 mol\% of a) $\mathrm{HC}_{-} \mathrm{PEG} 5 \mathrm{k}$ or b) in combination with a shorter length PEG spacer (MeO-PEG2k), given rise to NPs with different molar ratios of $\mathrm{HC}_{\mathrm{PEG}} \mathrm{k}$ and $\mathrm{MeO}-\mathrm{PEG} 2 \mathrm{k}$. Note: illustrative representation not to scale. 
a

Internalized NPs

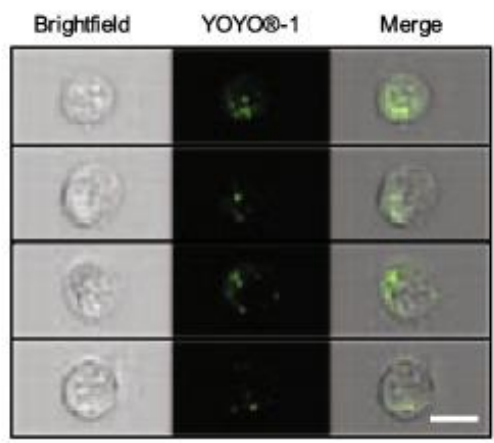

b

Membrane-bound NPs

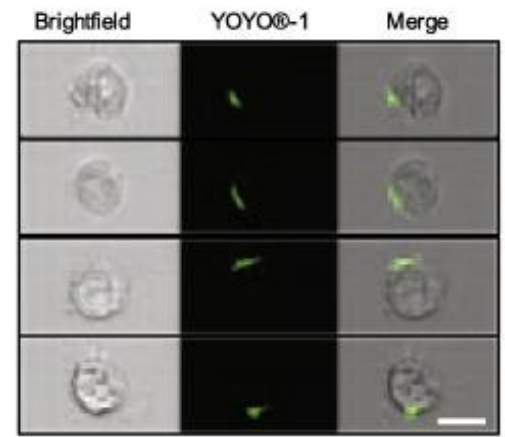

C

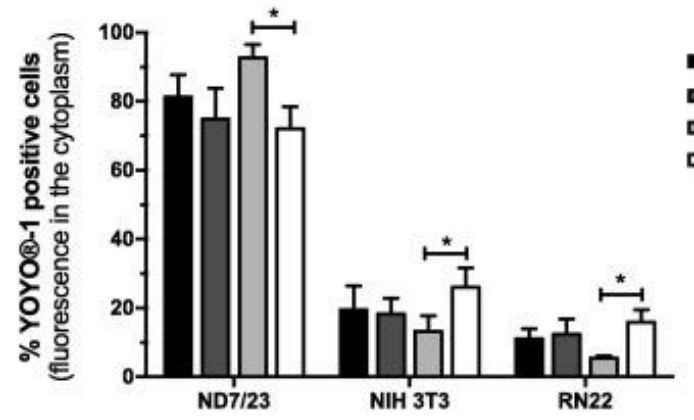

d
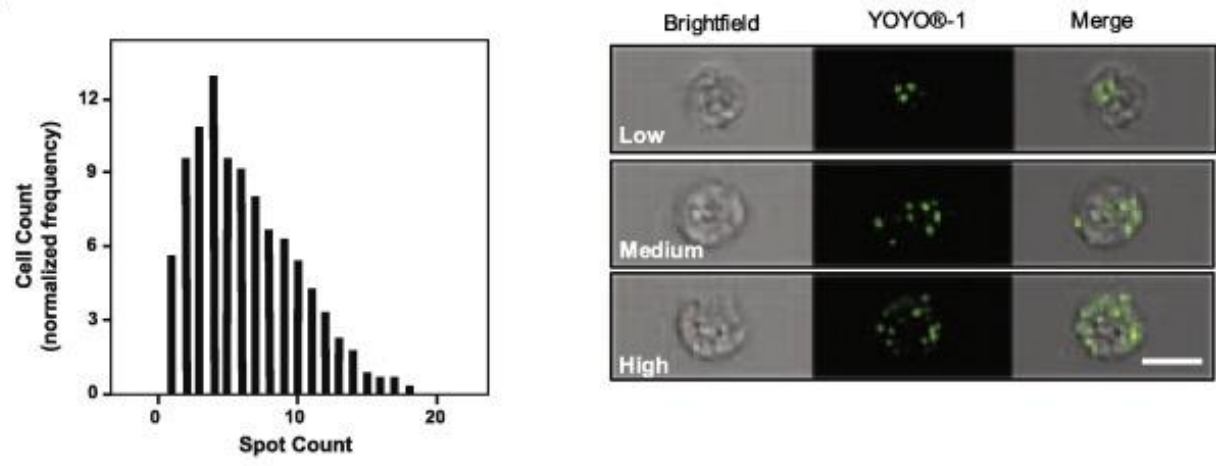

e

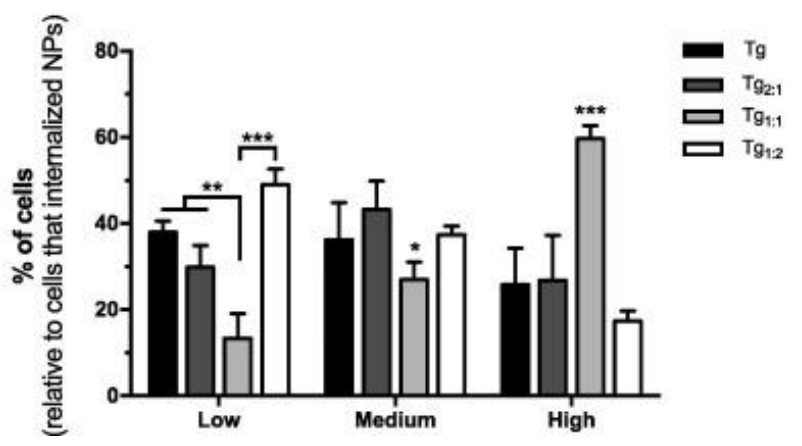

Fig. 3. Efficiency of cellular uptake and payload delivery mediated by neuron-targeted TMC NPs with different ratios of HC-PEG5k:MeO-PEG2k in neuronal versus non-neuronal cell lines. Representative bright-field, YOYO ${ }^{{ }_{-1}}$ (green fluorescence) and their overlays (scale bars: $10 \mu \mathrm{m}$ ) images acquired on ImageStreamX for ND7/23 cells 
that a) have internalized $Y_{O Y}{ }^{\circledR}{ }^{\circledR}-1$ labelled-pDNA or b) have $\mathrm{YOYO}^{\circledR}{ }_{-1}$ labelled-pDNA associated with the cellular membrane. c) Percentage of ND7/23, NIH and RN22 cells positive for YOYO ${ }^{\circledR}-1$ after a $2 \mathrm{~h}$ incubation with the different NP formulations. d) Histogram of NLV frequency obtained from IDEAS ${ }^{\circledR}$ software analysis and respective representative images of cells from the different gated regions (low, medium and high number of nanoparticleloaded vesicles (NLVs). e) Percentage of ND7/23 cells that had internalized low, medium or high amount of NLVs after $2 \mathrm{~h}$ incubation with the different NP formulations containing YOYO ${ }^{\circledR}-1$ labelled-pDNA. All data is represented as a mean of three independent experiments \pm SD. Multiple $t$ test analysis was used for comparisons between formulations. Statistical differences are presented as: $* p<0.05, * * p<0.01$ and $* * * p<0.001$. (For interpretation of the references to colour in this figure legend, the reader is referred to the web version of this article.)

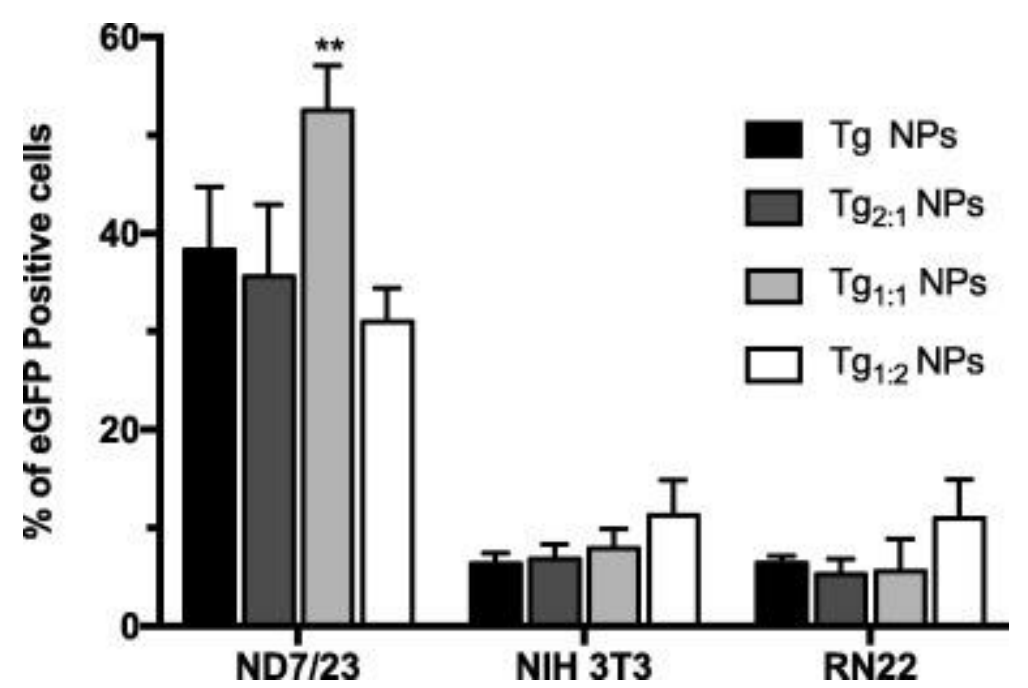

Fig. 4. Transfection efficiency of neuron-targeted TMC-based NPs with different ratios of HC-PEG $5 k$ :MeO-PEG2k in neuronal versus non-neuronal cell lines. The transfection efficiency of the different Tg NPs was evaluated $72 \mathrm{~h}$ post-transfection through the quantification of the percentage of cells expressing eGFP by flow cytometry. Untreated cells were used as control. Each bar represents the mean of three independent experiments \pm SD. Statistical differences are presented as: **p <0.01, when comparing the different NP formulations transfection efficiency in the ND7/23 cells. 
a
Mushroom-like
Brush-like
conformation
conformation

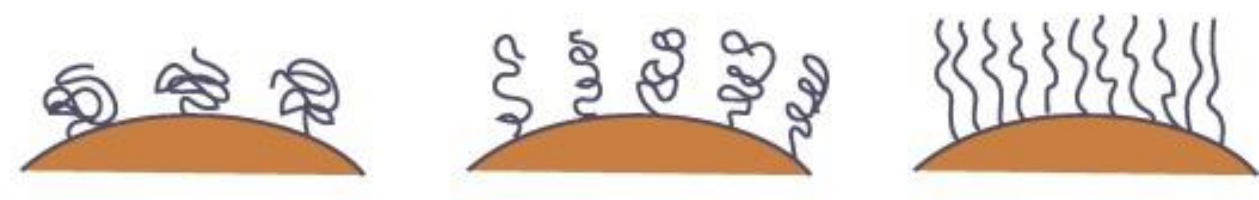

Polymer grafting density

b

Single chain PEGylation

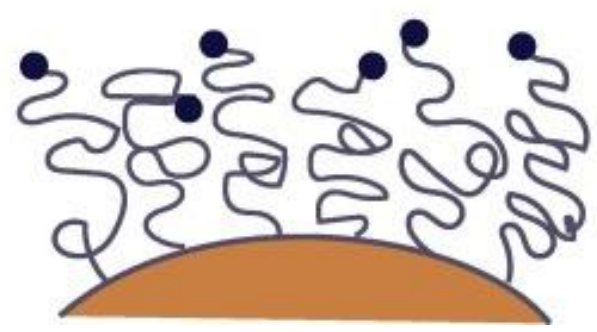

Mixed chain lengths PEGylation

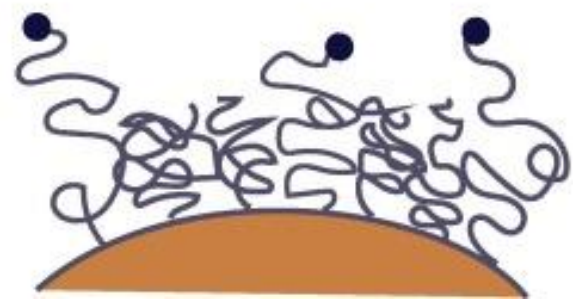

Scheme 4. Effect of spacer grafting density and length on conformation and ligand exposition. 
Table 1. Physicochemical characterization of neuron-targeted NPs functionalized with different molar ratios of HC-PEG5K/Meo-PEG2k.

$\begin{array}{lclc}\text { Formulation } & \text { Size }(\mathrm{nm}) & \text { Polydispersity index }(\mathrm{Pdl}) & \text { Zeta-potential }(\mathrm{mV}) \\ \mathrm{TgNPs} & 186 \pm 18 & 0.27 \pm 0.09 & +12.7 \pm 1.2 \\ \operatorname{Tg}_{2: 1} \mathrm{NPs} & 191 \pm 24 & 0.26 \pm 0.21 & +11.4 \pm 2.1 \\ \operatorname{Tg}_{1: 1} \mathrm{NPs} & 179 \pm 15 & 0.26 \pm 0.05 & +13.2 \pm 1.9 \\ & & & \\ \operatorname{Tg}_{1: 2} \mathrm{NPs} & 184 \pm 10 & 0.29 \pm 0.11 & +10.3 \pm 0.8\end{array}$

All NPs were prepared at N/P ratio of 8 with a final PEG grafting density of 2 mol\% of TMC primary amine groups. Average hydrodynamic sizes, polydispersity index and zeta potential were measured by dynamic light scattering in PBS, $\mathrm{pH} 7.4$ at $25^{\circ} \mathrm{C}$. Results from three independent experiments are represented as mean $\pm \mathrm{SD}$. 


\section{Supplementary Data}

Manuscript Title: Fine tuning neuronal targeting of nanoparticles by adjusting the ligand grafting density and combining PEG spacers of different length

Authors: Carla Pereira Gomes, Victoria Leiro, Cátia Daniela Ferreira Lopes, Ana Patrícia Spencer and Ana Paula Pêgo*

*corresponding author:

Ana Paula Pêgo, PhD

Principal Investigator

nBTT - nanoBiomaterials for Targeted Therapies Group

INEB - Instituto de Engenharia Biomédica (www.ineb.up.pt)

and

i3S - Instituto de Investigação e Inovação em Saúde (www.ỉs.up.pt)

Rua Alfredo Allen, 208 4200-135 Porto, Portugal Phone: +351-220408800

E-mail: apego@ineb.up.pt/apego@izs.up.pt

a

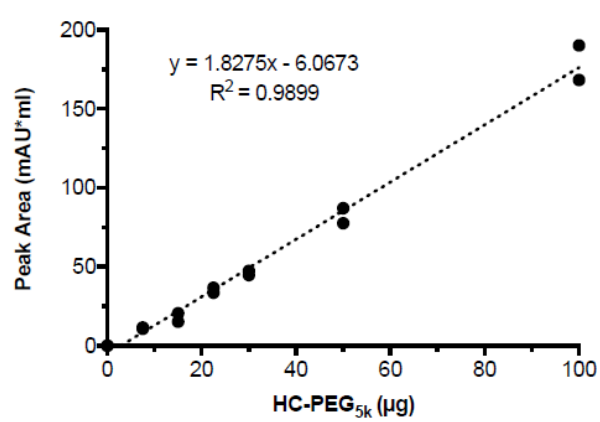

b

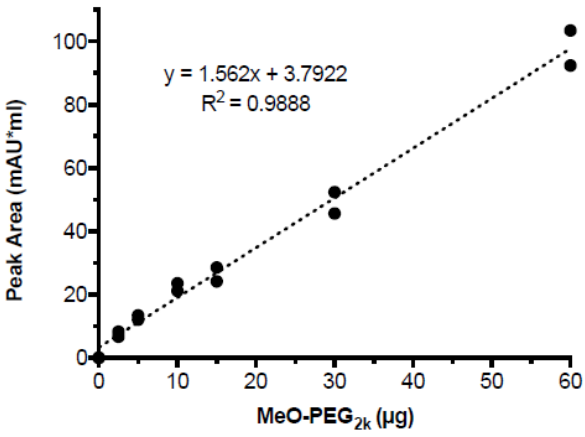

Fig. S1. Calibration curves used for the quantification of the amount of (a) HC-PEG 5 ( $58 \mathrm{kDa}$ ) and (b) MeO-PEG $_{2 \mathrm{k}}(2 \mathrm{kDa})$ in the supernatants of all developed NPs. The quantification was performed through the integration of the corresponding peaks of the SEC chromatograms (UV detection at 280 and $225 \mathrm{~nm}$; Retention volumes of 11.0 to $13.4 \mathrm{ml}$ for $\mathrm{HC}-\mathrm{PEG}_{5 \mathrm{k}}$, and $15.4 \mathrm{ml}$ for $\mathrm{MeO}-\mathrm{PEG}_{2 \mathrm{k}}$ ). 
Table S1. Efficiency of HC-PEG sk binding to NPs determined by size exclusion chromatography (SEC).

\begin{tabular}{|c|c|c|c|c|c|}
\hline & \multicolumn{3}{|c|}{ Supernatants } & \multicolumn{2}{|c|}{ Tg NP Functionalization } \\
\hline & 1 & 2 & 3 & 4 & 5 \\
\hline $\begin{array}{c}\text { Theoretical PEG } \\
\text { densities }\end{array}$ & $\begin{array}{l}\text { Peak Area } \\
\left(\mathrm{mAU}^{*} \mathrm{ml}\right)\end{array}$ & $\begin{array}{c}\text { HC-PEG } \\
(\mu \mathrm{g}) / 50 \mu \mathrm{l}\end{array}$ & $\begin{array}{l}\text { Total HC- } \\
\text { PEG }_{\text {sk }}(\mu \mathrm{g})\end{array}$ & $\begin{array}{c}\text { Initial } \mathrm{HC}-\mathrm{PEG}_{\text {sk }} \\
\text { mass }(\mu \mathrm{g})\end{array}$ & $\begin{array}{c}\text { Efficiency } \\
(\%)\end{array}$ \\
\hline $1 \mathrm{~mol} \%$ & $1.9 \pm 1.8$ & $3.9 \pm 1.0$ & $15.6 \pm 3.9$ & 384.8 & $95.9 \pm 1.1$ \\
\hline $2 \mathrm{~mol} \%$ & $10.7 \pm 6.2$ & $8.7 \pm 3.4$ & $34.8 \pm 13.6$ & 769.7 & $95.5 \pm 1.8$ \\
\hline $4 \mathrm{~mol} \%$ & $23.8 \pm 12.2$ & $15.9 \pm 6.7$ & $63.8 \pm 26.9$ & 1539.4 & $95.9 \pm 1.8$ \\
\hline
\end{tabular}

1) Peak Area (mAU*ml): Integration of the peak area (SEC chromatogram) corresponding to $\mathrm{HC}_{-} \mathrm{PEG}_{5 \mathrm{k}} ; 2$ ) $\mathrm{HC}$ $\mathrm{PEG}_{5 \mathrm{k}}(\mu \mathrm{g}) / 50 \mu \mathrm{l}: \mathrm{HC}-\mathrm{PEG}_{5 \mathrm{k}}$ mass contained in $50 \mu 1$ of supernatant; 3) Total HC-PEG $\mathrm{F}_{5 \mathrm{k}}(\mu \mathrm{g})$ : HC-PEG $\mathrm{H}_{5 \mathrm{k}}$ mass contained in the supernatants $(\mathrm{V}=200 \mu 1) ; 4)$ Initial mass of $\mathrm{HC}^{-P E G_{5 k}}$ added for preparing the $\mathrm{Tg} \mathrm{NP}$; 5 ) Efficiency of HC-PEG 5 binding to the NPs. Each value corresponds to the mean of two independent experiments $\pm \mathrm{SD}$.

Table S2. Physicochemical characterization of TMCSH polyplexes (NP core).

\begin{tabular}{ccccc}
\hline N/P ratio & Size $^{\mathbf{a}}(\mathbf{d} . \mathbf{n m})$ & $\begin{array}{c}\text { Polydispersity } \\
\text { Index }^{\mathbf{a}}(\mathbf{P d I})\end{array}$ & $\begin{array}{c}\text { Zeta-potential }^{\mathrm{b}} \\
(\mathbf{m V})\end{array}$ & $\begin{array}{c}\text { pDNA condensation } \\
\text { efficiency }^{\mathbf{c}}(\%)\end{array}$ \\
\hline $\mathbf{2}$ & $230 \pm 24$ & $0.32 \pm 0.12$ & $+15.3 \pm 1.7$ & $85.6 \pm 0.9$ \\
$\mathbf{4}$ & $207 \pm 20$ & $0.29 \pm 0.11$ & $+17.3 \pm 1.6$ & $89.2 \pm 1.5$ \\
$\mathbf{8}$ & $201 \pm 14$ & $0.30 \pm 0.08$ & $+18.6 \pm 1.4$ & $93.8 \pm 0.3$ \\
$\mathbf{1 2}$ & $196 \pm 14$ & $0.30 \pm 0.17$ & $+20.6 \pm 1.7$ & $92.6 \pm 0.8$ \\
\hline
\end{tabular}

${ }^{a} \mathrm{NP}$ average hydrodynamic sizes and PdI were measured by dynamic light scattering ( $\mathrm{n}=3 \pm \mathrm{SD}$ ).

${ }^{b}$ Mean surface charge of NPs based on zeta-potential measurements ( $n=3 \pm$ SD).

'Percentage of pDNA condensed into NPs assessed by SYBR Gold $(n=3 \pm S D)$.

All measurements were carried out in $20 \mathrm{mM}$ HBS $+5 \%(\mathrm{w} / \mathrm{v})$ glucose, $\mathrm{pH} 7.4$. 
Table S3. Percentage of YOYO 1 positive cells after incubation with nT or Tg NPs functionalized at different grafting densities.

$1 \mathrm{~mol} \%$ grafting density

\begin{tabular}{|c|c|c|c|c|c|c|}
\hline \multirow[b]{2}{*}{$\mathrm{N} / \mathrm{P}$ ratio } & \multicolumn{2}{|c|}{ ND7/23 } & \multicolumn{2}{|c|}{ NIH $3 \mathrm{~T} 3$} & \multicolumn{2}{|c|}{ RN22 } \\
\hline & nT NPs & Tg NPs & nT NPs & Tg NPs & nT NPs & Tg NPs \\
\hline 2 & $38.3 \pm 2.4$ & $75.8 \pm 3.8$ & $30.1 \pm 4.2$ & $37.7 \pm 3.9$ & $19.4 \pm 1.3$ & $26.7 \pm 5.2$ \\
\hline 4 & $35.8 \pm 3.8$ & $77.4 \pm 3.7$ & $35.4 \pm 3.9$ & $37.3 \pm 3.3$ & $25.1 \pm 2.8$ & $22.8 \pm 4.3$ \\
\hline 8 & $36.3 \pm 1.9$ & $91.3 \pm 7.3$ & $30.3 \pm 4.4$ & $29.1 \pm 6.2$ & $18.9 \pm 3.8$ & $19.3 \pm 2.2$ \\
\hline 12 & $22.4 \pm 4.2$ & $89.7 \pm 5.1$ & $55.8 \pm 6.3$ & $42.5 \pm 7.6$ & $24.8 \pm 2.7$ & $18.3 \pm 3.6$ \\
\hline \multicolumn{7}{|c|}{$2 \mathrm{~mol} \%$ grafting density } \\
\hline & \multicolumn{2}{|c|}{ ND7/23 } & \multicolumn{2}{|c|}{ NIH $3 \mathrm{~T} 3$} & \multicolumn{2}{|c|}{ RN22 } \\
\hline $\mathrm{N} / \mathrm{P}$ ratio & nT NPs & Tg NPs & nT NPs & Tg NPs & nT NPs & Tg NPs \\
\hline 2 & $35.5 \pm 3.8$ & $86.4 \pm 7.3$ & $28.7 \pm 2.8$ & $40.3 \pm 6.1$ & $18.4 \pm 2.6$ & $28.5 \pm 2.0$ \\
\hline 4 & $35.4 \pm 2.7$ & $91.2 \pm 8.5$ & $32.8 \pm 2.3$ & $39.9 \pm 5.6$ & $21.3 \pm 2.1$ & $20.2 \pm 3.3$ \\
\hline 8 & $31.2 \pm 2.5$ & $98.8 \pm 3.2$ & $29.4 \pm 3.4$ & $22.6 \pm 3.4$ & $16.8 \pm 1.9$ & $10.1 \pm 0.9$ \\
\hline 12 & $21.5 \pm 3.1$ & $95.4 \pm 5.2$ & $48.5 \pm 5.5$ & $41.4 \pm 2.7$ & $29.3 \pm 1.5$ & $17.8 \pm 0.5$ \\
\hline \multicolumn{7}{|c|}{$4 \mathrm{~mol} \%$ grafting density } \\
\hline & \multicolumn{2}{|c|}{$\mathrm{ND} 7 / 23$} & \multicolumn{2}{|c|}{ NIH $3 \mathrm{~T} 3$} & \multicolumn{2}{|c|}{ RN22 } \\
\hline $\mathrm{N} / \mathrm{P}$ ratio & nT NPs & Tg NPs & nT NPs & Tg NPs & nT NPs & Tg NPs \\
\hline 2 & $30.5 \pm 2.5$ & $85.3 \pm 6.1$ & $26.2 \pm 3.2$ & $44.6 \pm 2.1$ & $18.6 \pm 1.8$ & $23.3 \pm 3.1$ \\
\hline 4 & $26.5 \pm 3.6$ & $81.3 \pm 7.7$ & $28.4 \pm 2.9$ & $45.7 \pm 4.4$ & $18.3 \pm 1.3$ & $21.0=3.6$ \\
\hline 8 & $24.3 \pm 2.9$ & $94.5 \pm 4.3$ & $28.3 \pm 2.7$ & $34.4 \pm 2.8$ & $14.3 \pm 0.7$ & $12.6 \pm 1.9$ \\
\hline 12 & $22.1 \pm 4.1$ & $91.2 \pm 5.0$ & $35.1 \pm 3.0$ & $37.9 \pm 3.8$ & $18.7 \pm 2.2$ & $17.9 \pm 2.6$ \\
\hline
\end{tabular}

All measurements were carried out in a conventional flow cytometry. Untreated cells were used as control.

Each value corresponds to the mean of three independent experiments $\pm S D$.

Table S4. Percentage of YOYO\&-1 positive cells after incubation with TMC-based NPs prepared at different $\mathrm{N} / \mathrm{P}$ ratios.

\begin{tabular}{cccc}
\hline N/P ratio & ND7/23 & NIH 3T3 & RN22 \\
\hline $\mathbf{2}$ & $59.3 \pm 4.5$ & $38.9 \pm 2.6$ & $22.4 \pm 2.7$ \\
$\mathbf{4}$ & $68.7 \pm 5.6$ & $50.3 \pm 3.3$ & $30.7 \pm 6.2$ \\
$\mathbf{8}$ & $76.3 \pm 4.2$ & $55.4 \pm 4.8$ & $35.8 \pm 8.6$ \\
$\mathbf{1 2}$ & $84.2 \pm 8.6$ & $64.7 \pm 5.9$ & $40.6 \pm 1.8$ \\
\hline
\end{tabular}

All measurements were carried out in a conventional flow cytometry. Untreated cells were used as control

Each value corresponds to the mean of three independent experiments $\pm \mathrm{SD}$. 
Table S5. Efficiency of HC-PEG 5 sk and MeO-PEG 2 binding to the nanoparticles (NPs) determined by size exclusion chromatography (SEC).

\begin{tabular}{|c|c|c|c|c|c|c|c|c|c|c|}
\hline & \multicolumn{6}{|c|}{ Supernatants } & \multirow{2}{*}{\multicolumn{2}{|c|}{$\frac{\text { NP Functionalization }}{\text { Initial Mass }(\mu \mathrm{g})}$}} & \multicolumn{2}{|c|}{ Efficiency (\%) } \\
\hline & \multicolumn{3}{|c|}{$\mathrm{HC}-\mathrm{PEG}_{5 \mathrm{k}}$} & \multicolumn{3}{|c|}{ MeO-PEG 2 k } & & & & \\
\hline & $\bar{l}$ & 2 & 3 & 4 & 5 & 6 & 7 & 8 & 9 & 10 \\
\hline & $\begin{array}{l}\text { Peak Area } \\
\left(\mathrm{mAU}^{*} \mathrm{ml}\right)\end{array}$ & $\begin{array}{c}\mathrm{HC}- \\
\mathrm{PEG}_{5 \mathrm{k}} \\
(\mu \mathrm{g}) / \mathbf{5 0} \mu \mathrm{l}\end{array}$ & $\begin{array}{l}\text { Total HC- } \\
\text { PEG }_{\text {sk }}(\mu g)\end{array}$ & $\begin{array}{l}\text { Peak Area } \\
\left(\mathrm{mAU}^{*} \mathrm{ml}\right)\end{array}$ & $\begin{array}{c}\text { MeO- } \\
\text { PEG }_{2 \mathrm{k}} \\
(\mu \mathrm{g}) / \mathbf{5 0} \mu \mathrm{l}\end{array}$ & $\begin{array}{l}\text { Total MeO- } \\
\text { PEG }_{2 k}(\mu \mathrm{g})\end{array}$ & $\mathrm{HC}^{-} \mathrm{PEG}_{5 \mathrm{k}}$ & $\begin{array}{l}\text { MeO- } \\
\text { PEG }_{2 k}\end{array}$ & $\begin{array}{c}\text { HC- } \\
\text { PEG }_{\text {sk }}\end{array}$ & $\begin{array}{l}\text { MeO- } \\
\text { PEG }_{2 k}\end{array}$ \\
\hline $\mathrm{Tg}_{2: 1} \mathrm{NPs}$ & $18.1 \pm 5.2$ & $12.9 \pm 2.9$ & $385.6 \pm 86.5$ & 0 & 0 & 0 & $4652.2 \pm 1315.9$ & 125.0 & $91.7 \pm 0.5$ & $\geq 98.0$ \\
\hline $\mathrm{Tg}_{1: 1} \mathrm{NPs}$ & $16.9 \pm 10.5$ & $12.2 \pm 5.7$ & $364.2 \pm 173.6$ & 0 & 0 & 0 & $2221.8 \pm 2749.8$ & 189.4 & $89.8 \pm 2.1$ & $\geq 98.7$ \\
\hline $\mathrm{Tg}_{1: 2} \mathrm{NPs}$ & $6.6 \pm 2.3$ & $6.5 \pm 1.2$ & $193.8 \pm 34.9$ & 0 & 0 & 0 & $2291.4 \pm 648.1$ & 253.8 & $91.4 \pm 1.0$ & $\geq 99.0$ \\
\hline
\end{tabular}

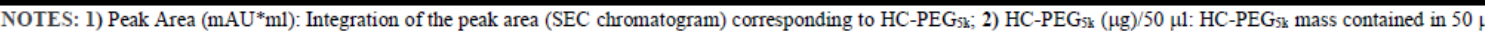

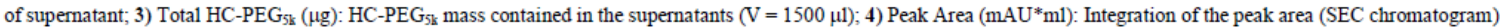

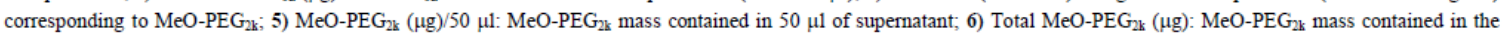

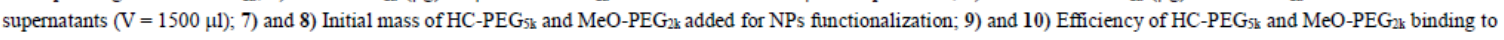
the nanoparticles, respectively.

For all cases, $\mathrm{MeO}-\mathrm{PEG}_{2 \mathrm{k}}$ was not detected in the supernatants. Considering the initial mass added for NP functionalization and the fact that the detection limit of the UV detector of the SEC system is of $2.5 \mu \mathrm{g}$, the efficiency of PEGylation with MeO-PEG $\mathrm{G}_{2 \mathrm{~s}}$ was always $\geq 98 \%$.

Each value corresponds to the mean of two independent experiments $\pm \mathrm{SD}$. 
Table S6. Percentage of YOYO ${ }^{\circledR}-1$ ND7/23 positive cells after a $2 \mathrm{~h}$ incubation with neuron-targeted NPs functionalized with hetero PEG brushes

\begin{tabular}{ll}
\hline Formulation & \% of positive cells \\
\hline Tg NPs & $97.6 \pm 3.5$ \\
Tg2:1 NPs & $94.5 \pm 6.3$ \\
Tgl:1 NPs & $96.4 \pm 4.8$ \\
Tgl:2 NPS & $92.1 \pm 7.1$ \\
\hline
\end{tabular}

All NPs were prepared at N/P ratio of 8 with a final grafting density of $2 \mathrm{~mol} \%$ per primary amine groups in TMC The percentage of YOYO 1 positive cells was evaluated by conventional flow cytometry.

Each value corresponds to the mean of two independent experiments performed with three replicates each $\pm \mathrm{SD}$.

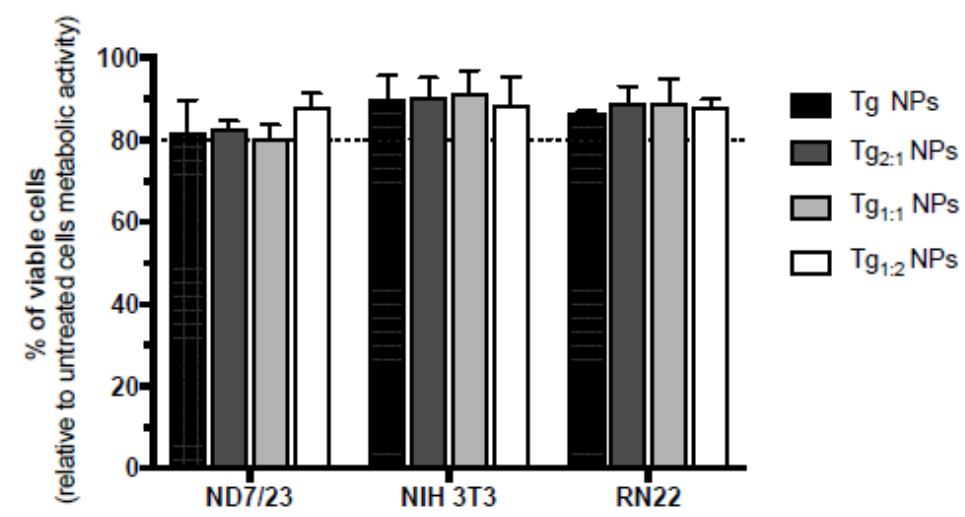

Fig. S2. Cytotoxicity profile of neuron-targeted NPs bearing hetero PEG brushes upon incubation in different cell lines. Cellular viability was assessed $72 \mathrm{~h}$ after cells incubation with the different neuron-targeted NPs by the resazurin reduction method. Results are expressed as percentage of cellular metabolic activity relative to untreated cells. Each bar represents the mean of three independent experiments $\pm S D$. 